\title{
On a Degenerate Evolution System Associated with the Bean Critical-State for Type II Superconductors
}

\author{
Junichi Aramaki \\ Division of Science, Faculty of Science and Engineering, Tokyo Denki University, Hatoyama-Machi, Saitama 350-0394, Japan \\ Correspondence should be addressed to Junichi Aramaki; aramaki@mail.dendai.ac.jp
}

Received 5 March 2015; Revised 1 November 2015; Accepted 3 November 2015

Academic Editor: Naseer Shahzad

Copyright (C) 2015 Junichi Aramaki. This is an open access article distributed under the Creative Commons Attribution License, which permits unrestricted use, distribution, and reproduction in any medium, provided the original work is properly cited.

\begin{abstract}
We study a degenerate evolution system containing the $p$-curl system in a bounded domain with initial and boundary conditions for the magnetic field $\mathbf{H}$ under the influence of a system force $\mathbf{F}$. This is concerned with an approximation of Bean's critical-state model for type II superconductors. We will show the existence, uniqueness, and regularity of solutions. Moreover we will get the properties of the limit solution as $p \rightarrow \infty$.
\end{abstract}

\section{Introduction}

The Bean critical-state model describes the hysteretic magnetization of type II superconductors under a varying external magnetic field (cf. Prigozhin [1] and de Gennes [2]). For the description of the classical Bean critical-state model, Yin et al. [3] proposed the following degenerate evolution system:

$$
\begin{aligned}
\mathbf{H}_{t}+\operatorname{curl}\left[|\operatorname{curl} \mathbf{H}|^{p-2} \operatorname{curl} \mathbf{H}\right] & =\mathbf{F}(x, t) \quad \text { in } Q_{T}, \\
\operatorname{div} \mathbf{H} & =0 \quad \text { in } Q_{T}, \\
\boldsymbol{v} \times \mathbf{H} & =\mathbf{0} \quad \text { on } \partial \Omega \times[0, T], \\
\mathbf{H}(x, 0) & =\mathbf{H}_{0}(x) \quad \text { in } \Omega,
\end{aligned}
$$

where $\Omega$ is a bounded domain with $C^{1,1}$ boundary $\partial \Omega$ and has no holes in $\mathbb{R}^{3}, Q_{T}=\Omega \times(0, T](T>0)$, and $\boldsymbol{\nu}$ denotes the outward normal unit vector field to $\partial \Omega$, and $p \geq 2$. In the Bean model, the electric field $\mathbf{E}$ and the current density $\mathbf{J}$ are characterized as follows. There exists a critical current $J_{c}$ such that $|\mathrm{J}| \leq J_{c}$ in $\Omega$ and

$$
|\mathbf{E}|= \begin{cases}0 & \text { if }|\mathbf{J}|<J_{c}, \\ {[0, \infty)} & \text { if }|\mathbf{J}|=J_{c} .\end{cases}
$$

Thus if $|\mathbf{J}|$ reaches $J_{c}$, then $|\mathbf{E}|$ takes the value in $[0, \infty)$. By scaling, we may assume that $J_{c}=1$. The relation between $|\mathrm{E}|$ and $|\mathbf{J}|$ is followed from the Ampere law:

$$
\mathbf{E}=|\operatorname{curl} \mathbf{H}|^{p-2} \operatorname{curl} \mathbf{H}
$$

as $p \rightarrow \infty$. Here $\mathbf{H}$ is the magnetic field and $\rho=|\operatorname{curl} \mathbf{H}|^{p-2}$. Thus model (1) provides a good approximation for the Bean model. For large $p$, the resistivity $\rho$ is small in a region

$$
S_{\varepsilon}=\{(x, t) ;|\operatorname{curl} \mathbf{H}(x, t)| \leq 1-\varepsilon\} \quad \text { for } \varepsilon>0 .
$$

That is to say, $S_{\varepsilon}$ becomes the superconductivity region as $p \rightarrow \infty$. For more details, see Bean [3, 4] and references therein. Though the authors in [3] considered system (1)(4), there are many mistakes and mistypes; for example, in Definition 2.1 (page 786), the differentiability of $\mathbf{H}$ with respect to the time variable $t$ is not assumed, and they mistake the notion of the subdifferential (pages 788, 791-793) and so forth.

In this paper, we will extend the results of [3] to more general resistivity term of the form $\rho=g(x,|\operatorname{curl} \mathbf{H}|)$ for some function $g$. Since the resistivity $\rho=g(x,|\operatorname{curl} \mathbf{H}|)$ may be of the form not only $g(x,|\operatorname{curl} \mathbf{H}|)=|\operatorname{curl} \mathbf{H}|^{p-2}$ but also $g(x,|\operatorname{curl} \mathbf{H}|)=a(x)|\operatorname{curl} \mathbf{H}|^{p-2}$ or more general type, we are convinced that the extension is meaningful. 
This paper is organized as follows. In Section 2, we introduce some spaces of vector fields and describe the setting of the problem. In Section 3, we consider the existence, uniqueness, and regularity of the solution for the problem. Finally, in Section 4, we examine the properties of the limit solution $\mathbf{H}^{(\infty)}(x, t)$ as $p \rightarrow \infty$. The result shows that the resistivity $\rho$ vanishes in the region $S=\left\{(x, t) ; \mid \operatorname{curl} \mathbf{H}^{(\infty)}(x\right.$, $t) \mid<1\}$.

\section{Preliminaries and the Setting of the Problem}

In this section, we introduce some spaces of vector fields which are used in this paper and set the problem.

Let $\Omega \subset \mathbb{R}^{3}$ be a bounded domain with $C^{1,1}$ boundary. Throughout this paper, we assume that $\Omega$ has no holes. That is to say, the second Betti number of $\Omega$ is equal to zero. This means that

$$
\begin{aligned}
\{\mathbf{G} & \in L^{p}\left(\Omega, \mathbb{R}^{3}\right) ; \operatorname{curl} \mathbf{G}=\mathbf{0}, \operatorname{div} \mathbf{G}=0 \text { in } \Omega, \boldsymbol{\nu} \times \mathbf{G} \\
= & \mathbf{0} \text { on } \partial \Omega\}=\{\mathbf{0}\} .
\end{aligned}
$$

But we allow $\Omega$ to be not simply connected. For these notations, see Dautray and Lions [5] or Amrouche and Seloula [6]. Let $p \geq 2$ and define some spaces of vector fields defined in $\Omega$ with values in $\mathbb{R}^{3}$. One has

$$
\begin{aligned}
& H^{p}(\operatorname{curl}, \Omega) \\
& \quad=\left\{\mathbf{G} \in L^{p}\left(\Omega, \mathbb{R}^{3}\right) ; \operatorname{curl} \mathbf{G} \in L^{p}\left(\Omega, \mathbb{R}^{3}\right)\right\} .
\end{aligned}
$$

We note that, for $\mathbf{G} \in H^{p}(\operatorname{curl}, \Omega)$, the tangential trace $\boldsymbol{\nu} \times \mathbf{G}$ is well defined in $W^{-1 / p, p}\left(\partial \Omega, \mathbb{R}^{3}\right)$ (cf. [6]). And moreover, define

$$
\begin{aligned}
& H_{0}^{p}(\operatorname{curl}, \Omega) \\
& \quad=\left\{\mathbf{G} \in H^{p}(\operatorname{curl}, \Omega) ; \boldsymbol{v} \times \mathbf{G}=\mathbf{0} \text { on } \partial \Omega\right\}, \\
& H_{0}^{p}(\operatorname{curl}, \operatorname{div}, \Omega) \\
& \quad=\left\{\mathbf{G} \in H_{0}^{p}(\operatorname{curl}, \Omega) ; \operatorname{div} \mathbf{G} \in L^{p}(\Omega)\right\}, \\
& H_{0}^{p}(\operatorname{curl}, \operatorname{div} 0, \Omega) \\
& \quad=\left\{\mathbf{G} \in H_{0}^{p}(\operatorname{curl}, \Omega) ; \operatorname{div} \mathbf{G}=0 \text { in } \Omega\right\} .
\end{aligned}
$$
Pan [8].

The following lemma follows from [6], Aramaki [7], and

Lemma 1. If $\Omega$ has no holes, then

$$
H_{0}^{p}(\operatorname{curl}, \operatorname{div} 0, \Omega) \subset H_{0}^{p}(\operatorname{curl}, \operatorname{div}, \Omega) \subset W^{1, p}\left(\Omega, \mathbb{R}^{3}\right)
$$

and the norm in $H_{0}^{p}($ curl, div0, $\Omega)$ given by

$$
\|\operatorname{curl} \mathbf{G}\|_{L^{p}(\Omega)}, \quad \mathbf{G} \in H_{0}^{p}(\operatorname{curl}, \operatorname{div}, \Omega)
$$

is equivalent to the norm in $W^{1, p}\left(\Omega, \mathbb{R}^{3}\right)$. In particular, $H_{0}^{p}(\operatorname{curl}, \operatorname{div} 0, \Omega)$ is a Banach space with the norm $\|\operatorname{curl} \mathbf{G}\|_{L^{p}(\Omega)}$.
By the Sobolev embedding theorem, we can get the following.

Lemma 2. Assume that $\Omega$ is bounded domain in $\mathbb{R}^{3}$ without holes and with $C^{1,1}$ boundary. If $\mathbf{G} \in H_{0}^{p}$ (curl, div, $\Omega$ ), then

$$
\begin{gathered}
\|\mathbf{G}\|_{L^{3 p /(3-p)}(\Omega)} \leq C\left(\|\operatorname{curl} \mathbf{G}\|_{L^{p}(\Omega)}+\|\operatorname{div} \mathbf{G}\|_{L^{p}(\Omega)}\right) \\
\text { if } p \in(1,3), \\
\|\mathbf{G}\|_{L^{q}(\Omega)} \leq C\left(\|\operatorname{curl} \mathbf{G}\|_{L^{p}(\Omega)}+\|\operatorname{div} \mathbf{G}\|_{L^{p}(\Omega)}\right) \\
\text { for any } 1<q<\infty \text { if } p=3, \\
\|\mathbf{G}\|_{C^{\alpha}(\bar{\Omega})} \leq C\left(\|\operatorname{curl} \mathbf{G}\|_{L^{p}(\Omega)}+\|\operatorname{div} \mathbf{G}\|_{L^{p}(\Omega)}\right) \\
\text { if } p>3,
\end{gathered}
$$

where $\alpha=1-3 / p$.

Throughout this paper we denote the norm of vector field $\mathbf{G}$ in $L^{p}\left(\Omega, \mathbb{R}^{3}\right)$ or $W^{1, p}\left(\Omega, \mathbb{R}^{3}\right)$ by $\|\mathbf{G}\|_{L^{p}(\Omega)}$ or $\|\mathbf{G}\|_{W^{1, p}(\Omega)}$, respectively.

Let $p \geq 2$. We assume that the function $\Omega \times[0, T] \ni$ $(x, s) \rightarrow f_{p}(x, s)$ satisfies the following.

(H.1) $f_{p}(x, s) \in C^{1}(\Omega \times[0, T]) \cap C^{2}(\Omega \times(0, T])$ with $f_{p}(x, 0)=0$ satisfies that there exist $\lambda, \Lambda>0$ independent of $x, s$, and $p$ such that

$$
\begin{aligned}
& \lambda s^{(p-2) / 2} \leq f_{p}^{\prime}(x, s) \leq \Lambda s^{(p-2) / 2} \text { for } s \geq 0, \\
& 0 \leq f_{p}^{\prime \prime}(x, s) \leq \Lambda s^{(p-4) / 2} \text { for } s>0,
\end{aligned}
$$

where $f_{p}^{\prime}(x, s)=\left(\partial f_{p} / \partial s\right)(x, s)$ and $f_{p}^{\prime \prime}(x, s)=\left(\partial^{2} f_{p} / \partial s^{2}\right)(x$, $s)$. Then it is clear that $f$ satisfies

$$
\frac{2}{p} \lambda s^{p / 2} \leq f_{p}(x, s) \leq \frac{2}{p} \Lambda s^{p / 2}
$$

and $f_{p}(x, s)$ is convex with respect to $s$ variable.

We consider the initial and boundary value problem:

$$
\begin{aligned}
\mathbf{H}_{t}+\operatorname{curl}\left[f_{p}^{\prime}\left(x,|\operatorname{curl} \mathbf{H}|^{2}\right) \operatorname{curl} \mathbf{H}\right] & =\mathbf{F}(x, t) \\
\operatorname{div} \mathbf{H} & =0 \quad \text { in } Q_{T}, \\
\nu \times \mathbf{H} & =\mathbf{0} \\
& \text { on } \partial \Omega \times[0, T], \\
\mathbf{H}(x, 0) & =\mathbf{H}_{0}(x) \quad \text { in } \Omega,
\end{aligned}
$$

where $\mathbf{F}$ and $\mathbf{H}_{0}$ are given vector fields. We assume the following.

(H.2) $\mathbf{F}=\mathbf{F}(x, t) \in L^{2}\left(0, T ; L^{2}(\Omega)\right)$ satisfies $\operatorname{div} \mathbf{F}=0$ in $Q_{T}$ and $\mathbf{F} \cdot \boldsymbol{v}=0$ on $\partial \Omega$ for a.e. $t \in(0, T]$, and $\mathbf{H}_{0}=\mathbf{H}_{0}(x)$ satisfies that $\mathbf{H}_{0} \in H_{0}^{p}(\operatorname{curl}$, div0, $\Omega)$ and $\operatorname{curl}\left[f_{s}^{\prime}\left(x,\left|\operatorname{curl} \mathbf{H}_{0}\right|^{2}\right) \operatorname{curl} \mathbf{H}_{0}\right] \in L^{2}\left(\Omega, \mathbb{R}^{3}\right)$.

We note that hypothesis (H.2) contains the compatibility conditions: $\operatorname{div} \mathbf{F}=0$ in $Q_{T}$ and $\boldsymbol{\nu} \times \mathbf{H}_{0}=\mathbf{0}$ on $\partial \Omega$. 
Example 3. $f_{p}(x, s)=(2 / p) a(x) s^{p / 2}$ where $a \in C^{2}(\bar{\Omega})$ with $0<c_{1} \leq a(x) \leq c_{2}<\infty$ satisfying (H.1). In particular, if $a(x) \equiv 1$, system (16)-(19) becomes (1)-(4).

The following definition of solution of system (16)-(19) is based on Brezis [9, Definition 3.1].

Definition 4. One calls a vector field $\mathbf{H}=\mathbf{H}(x, t)$, a solution of system (16)-(19), if the following hold:

(i) $\mathbf{H} \in C\left([0, T] ; L^{2}(\Omega)\right)$ and is absolutely continuous with respect to $t$ in all compact subset of $(0, T)$, and for a.e. $t \in(0, T), \mathbf{H}_{t} \in L^{2}\left(\Omega, \mathbb{R}^{3}\right)$ (therefore for a.e. $t \in(0, T), \mathbf{H}$ is differentiable with respect to $t)$;

(ii) $\mathbf{H}(x, t) \in H_{0}^{p}$ (curl, div0, $\Omega$ ) for a.e. $t \in(0, T)$;

(iii) $\operatorname{curl}\left[f_{p}^{\prime}\left(x,|\operatorname{curl} \mathbf{H}|^{2}\right) \operatorname{curl} \mathbf{H}\right] \in L^{2}\left(\Omega, \mathbb{R}^{3}\right)$ for a.e. $t \in$ $(0, T)$;

(iv) (16) holds in $L^{2}\left(\Omega, \mathbb{R}^{3}\right)$ for a.e.t $\in(0, T)$ and $\mathbf{H}(x, 0)=$ $\mathbf{H}_{0}(x)$ in $\Omega$.

(One notes that, for a.e. $t \in(0, T), \mathbf{H}$ is differentiable with respect to $t$.)

Here we give Green's formula which will be used frequently later (cf. [6]).

Lemma 5. For $\mathbf{A} \in H^{p}$ (curl, $\Omega$ ) and $\mathbf{B} \in W^{1, p^{\prime}}\left(\Omega, \mathbb{R}^{3}\right)$ where $p^{\prime}$ is the conjugate exponent for $p$, that is to say, $p^{\prime}=p /(p-1)$, then one has

$$
\int_{\Omega} \operatorname{curl} \mathbf{A} \cdot \mathbf{B} d x-\int_{\Omega} \mathbf{A} \cdot \operatorname{curl} \mathbf{B} d x=\langle\boldsymbol{\nu} \times \mathbf{A}, \mathbf{B}\rangle_{\partial \Omega},
$$

where $\mathbf{a} \cdot \mathbf{b}$ denotes the usual inner product for vectors $\mathbf{a}$ and $\mathbf{b}$ in $\mathbb{R}^{3}$ and $\langle\cdot, \cdot\rangle_{\partial \Omega}$ denotes the duality between $W^{-1 / p, p}(\partial \Omega)$ and $W^{1-1 / p^{\prime}, p^{\prime}}(\partial \Omega)$.

\section{Existence, Uniqueness, and Regularity of Solution}

In this section, we will consider the existence and uniqueness for system (16)-(19) and also regularity under more restrictive hypotheses on $\mathbf{F}$.

Theorem 6. Let $p \geq 2$. Assume that $\Omega$ is a bounded domain in $\mathbb{R}^{3}$ without holes and with $C^{1,1}$ boundary. Under hypotheses (H.1) and (H.2), system (16)-(19) has a unique solution in the sense of Definition 4. Moreover, one has $\mathbf{H}_{t} \in L^{2}\left(Q_{T}\right)$ and $\mathbf{H} \epsilon$ $L^{\infty}\left(0, T ; H_{0}^{p}(\operatorname{curl}, \operatorname{div} 0, \Omega)\right)$.

The proof will be achieved by applying theorems due to Brezis [9, Theorems 3.4 and 3.6]. In order to do so, define a Hilbert space $X=L^{2}\left(\Omega, \mathbb{R}^{3}\right)$ and a functional $I_{p}[\mathbf{V}]$ for $\mathbf{V} \in$ $X$ by

$$
\begin{aligned}
& I_{p}[\mathbf{V}] \\
& = \begin{cases}\frac{1}{2} \int_{\Omega} f_{p}\left(x,|\operatorname{curl} \mathbf{V}|^{2}\right) d x & \text { if } \mathbf{V} \in H_{0}^{p}(\operatorname{curl}, \operatorname{div} 0, \Omega), \\
+\infty & \text { otherwise. }\end{cases}
\end{aligned}
$$

It is clear that the effective domain $D\left(I_{p}\right)=H_{0}^{p}$ (curl, div0, $\Omega) \neq \emptyset$.

Lemma 7. Under hypothesis (H.1), $I_{p}$ is a proper lower semicontinuous and convex functional.

Proof. First we show that $I_{p}$ is lower semicontinuous; that is, if $\mathbf{V}_{n} \rightarrow \mathbf{V}$ in $L^{2}\left(\Omega, \mathbb{R}^{3}\right)$ as $n \rightarrow \infty$, then $I_{p}[\mathbf{V}] \leq$ $\liminf _{n \rightarrow \infty} I_{p}\left[\mathbf{V}_{n}\right]$. This is equivalent to show that if $\mathbf{V}_{n} \rightarrow \mathbf{V}$ in $L^{2}\left(\Omega, \mathbb{R}^{3}\right)$ as $n \rightarrow \infty$ and $\lim _{n \rightarrow \infty} I_{p}\left[\mathbf{V}_{n}\right]=I$, then $I_{p}[\mathbf{V}] \leq I$. In fact, it is clear from the fact that if $\mathbf{V}_{n} \rightarrow \mathbf{V}$ in $L^{2}\left(\Omega, \mathbb{R}^{3}\right)$, there exists a subsequence $\left\{\mathbf{V}_{n_{k}}\right\}$ of $\left\{\mathbf{V}_{n}\right\}$ such that

$$
\liminf _{n \rightarrow \infty} I_{p}\left[\mathbf{V}_{n}\right]=\lim _{k \rightarrow \infty} I_{p}\left[\mathbf{V}_{n_{k}}\right]
$$

Thus we assume that $\mathbf{V}_{n} \rightarrow \mathbf{V}$ in $L^{2}\left(\Omega, \mathbb{R}^{3}\right)$ and $\lim _{n \rightarrow \infty} I_{p}\left[\mathbf{V}_{n}\right]=I$. We show that $I_{p}[\mathbf{V}] \leq I$. If $I=+\infty$, it is trivial, so we may assume that $I<\infty$. Choosing a subsequence, if necessary, we may assume that $I_{p}\left[\mathbf{V}_{n}\right]<\infty$ and

$$
\frac{1}{2} \int_{\Omega} f_{p}\left(x,\left|\operatorname{curl} \mathbf{V}_{n}\right|^{2}\right) d x=I+o(1),
$$

as $n \rightarrow \infty$. Thus we have $\mathbf{V}_{n} \in H_{0}^{p}(\operatorname{curl}, \operatorname{div} 0, \Omega)$ and it follows from (H.1) that

$$
\begin{aligned}
\frac{\lambda}{p} \int_{\Omega}\left|\operatorname{curl} \mathbf{V}_{n}\right|^{p} d x & \leq \frac{1}{2} \int_{\Omega} f_{p}\left(x,\left|\operatorname{curl} \mathbf{V}_{n}\right|^{2}\right) d x \\
& =I+o(1) \leq I+1<\infty .
\end{aligned}
$$

Since $\Omega$ has no holes, it follows from Lemma 1 that $\left\{\mathbf{V}_{n}\right\}$ is bounded in $W^{1, p}\left(\Omega, \mathbb{R}^{3}\right)$. Passing to a subsequence, we may assume that $\mathbf{V}_{n} \rightarrow \widetilde{\mathbf{V}}$ weakly in $W^{1, p}\left(\Omega, \mathbb{R}^{3}\right)$ and from the compactness of embedding from $W^{1, p}\left(\Omega, \mathbb{R}^{3}\right)$ to $L^{p}\left(\Omega, \mathbb{R}^{3}\right)$, $\mathbf{V}_{n} \rightarrow \widetilde{\mathbf{V}}$ strongly in $L^{p}\left(\Omega, \mathbb{R}^{3}\right)$. Since $p \geq 2$, we have $\widetilde{\mathbf{V}}=\mathbf{V}$. Since $f_{p}^{\prime \prime}(x, s) \geq 0$ for all $s>0$ and $f_{p}^{\prime}(x, s) \geq 0$ for all $s \geq 0$, taking the Taylor theorem into consideration, we have

$$
\begin{aligned}
& \int_{\Omega} f_{p}\left(x,\left|\operatorname{curl} \mathbf{V}_{n}\right|^{2}\right) d x-\int_{\Omega} f_{p}\left(x,|\operatorname{curl} \mathbf{V}|^{2}\right) d x \\
& \quad=\int_{\Omega} f_{p}\left(x,\left|\operatorname{curl} \mathbf{V}+\operatorname{curl} \mathbf{V}_{n}-\operatorname{curl} \mathbf{V}\right|^{2}\right) d x \\
& -\int_{\Omega} f_{p}\left(x,|\operatorname{curl} \mathbf{V}|^{2}\right) d x=\int_{\Omega} f_{p}\left(x,|\operatorname{curl} \mathbf{V}|^{2}\right. \\
& +2 \operatorname{curl} \mathbf{V} \cdot\left(\operatorname{curl} \mathbf{V}_{n}-\operatorname{curl} \mathbf{V}\right) \\
& \left.+\left|\operatorname{curl} \mathbf{V}_{n}-\operatorname{curl} \mathbf{V}\right|^{2}\right) d x \\
& -\int_{\Omega} f_{p}\left(x,|\operatorname{curl} \mathbf{V}|^{2}\right) d x \geq \int_{\Omega} f_{p}^{\prime}\left(x,|\operatorname{curl} \mathbf{V}|^{2}\right) \\
& \cdot\left\{2 \operatorname{curl} \mathbf{V} \cdot\left(\operatorname{curl} \mathbf{V}_{n}-\operatorname{curl} \mathbf{V}\right)\right. \\
& \left.+\left|\operatorname{curl} \mathbf{V}_{n}-\operatorname{curl} \mathbf{V}\right|^{2}\right\} d x
\end{aligned}
$$




$$
\begin{aligned}
& \geq 2 \int_{\Omega} f_{p}^{\prime}\left(x,|\operatorname{curl} \mathbf{V}|^{2}\right) \operatorname{curl} \mathbf{V} \cdot\left(\operatorname{curl} \mathbf{V}_{n}\right. \\
& -\operatorname{curl} \mathbf{V}) d x
\end{aligned}
$$

Since

$$
\begin{gathered}
\int_{\Omega}\left|f_{p}^{\prime}\left(x,|\operatorname{curl} \mathbf{V}|^{2}\right) \operatorname{curl} \mathbf{V}\right|^{p^{\prime}} d x \\
\leq \Lambda^{p^{\prime}} \int_{\Omega}|\operatorname{curl} \mathbf{V}|^{p} d x<\infty
\end{gathered}
$$

and curl $\mathbf{V}_{n} \rightarrow$ curl V weakly in $L^{p}\left(\Omega, \mathbb{R}^{3}\right)$, it follows from the Hölder inequality that the last term of (25) tends to zero as $n \rightarrow \infty$. Thus

$$
\begin{aligned}
I & =\liminf _{n \rightarrow \infty} \frac{1}{2} \int_{\Omega} f_{p}\left(x,\left|\operatorname{curl} \mathbf{V}_{n}\right|^{2}\right) d x \\
& \geq \frac{1}{2} \int_{\Omega} f_{p}\left(x,|\operatorname{curl} \mathbf{V}|^{2}\right) d x=I_{p}[\mathbf{V}] .
\end{aligned}
$$

Next we show that $I_{p}$ is convex; that is, for any $\mathbf{V}$ and $\mathbf{W}$ in $L^{2}\left(\Omega, \mathbb{R}^{3}\right)$ and any $0<\mu<1$,

$$
I_{p}[\mu \mathbf{V}+(1-\mu) \mathbf{W}] \leq \mu I_{p}[\mathbf{V}]+(1-\mu) I_{p}[\mathbf{W}]
$$

When $\mathbf{V}$ or $\mathbf{W}$ does not belong to $H_{0}^{p}(\operatorname{curl}, \operatorname{div} 0, \Omega), I_{p}[\mathbf{V}]=$ $+\infty$, or $I_{p}[\mathbf{W}]=+\infty$, the inequality is trivial. Thus let $\mathbf{V}$ and W be in $H_{0}^{p}\left(\right.$ curl, div0, $\Omega$ ). Since a function $[0, \infty) \ni s \mapsto s^{2}$ is convex and for each $x \in \Omega$, the function $s \rightarrow f_{p}(x, s)$ is an increasing function and convex with respect to $s$, for any $s_{1}, s_{2} \geq 0$,

$$
\begin{aligned}
& f_{p}\left(x,\left(\mu s_{1}+(1-\mu) s_{2}\right)^{2}\right) \leq f_{p}\left(x, \mu s_{1}^{2}+(1-\mu) s_{2}^{2}\right) \\
& \quad \leq \mu f_{p}\left(x, s_{1}^{2}\right)+(1-\mu) f_{p}\left(x, s_{2}^{2}\right) .
\end{aligned}
$$

Therefore it is easily shown that $I_{p}$ is convex.

Now we consider the subdifferential of the functional $I_{p}$ (cf. Struwe [10, page 58]). The domain of the subdifferential $\partial I_{p}$ is defined by

$$
\begin{aligned}
& D\left(\partial I_{p}\right)=\left\{\mathbf{H} \in D\left(I_{p}\right) ; \text { there exists } \mathbf{U}\right. \\
& \quad \in L^{2}\left(\Omega, \mathbb{R}^{3}\right) \text { such that } I_{p}[\mathbf{V}]-I_{p}[\mathbf{H}] \\
& \left.\quad \geq(\mathbf{U}, \mathbf{V}-\mathbf{H}) \quad \forall \mathbf{V} \in L^{2}\left(\Omega, \mathbb{R}^{3}\right)\right\},
\end{aligned}
$$

where $(\mathbf{U}, \mathbf{V})=\int_{\Omega} \mathbf{U} \cdot \mathbf{V} d x$ is the usual inner product of $\mathbf{U}$ and $\mathbf{V}$ in $L^{2}\left(\Omega, \mathbb{R}^{3}\right)$. If $\mathbf{V} \notin H_{0}^{p}(\operatorname{curl}, \operatorname{div} 0, \Omega)$, then $I_{p}[\mathbf{V}]=+\infty$, so we can rewrite

$$
\begin{aligned}
& D\left(\partial I_{p}\right)=\left\{\mathbf{H} \in D\left(I_{p}\right) ; \text { there exists } \mathbf{U}\right. \\
& \quad \in L^{2}\left(\Omega, \mathbb{R}^{3}\right) \text { such that } I_{p}[\mathbf{V}]-I_{p}[\mathbf{H}] \\
& \left.\quad \geq(\mathbf{U}, \mathbf{V}-\mathbf{H}) \quad \forall \mathbf{V} \in H_{0}^{p}(\operatorname{curl}, \operatorname{div} 0, \Omega)\right\} .
\end{aligned}
$$

Then the multivalued subdifferential $\partial I_{p}$ at $\mathbf{H} \in D\left(I_{p}\right)$ is defined by

$$
\begin{gathered}
\partial I_{p}[\mathbf{H}]=\left\{\mathbf{U} \in L^{2}\left(\Omega, \mathbb{R}^{3}\right) ; I_{p}[\mathbf{V}]-I_{p}[\mathbf{H}]\right. \\
\left.\geq(\mathbf{U}, \mathbf{V}-\mathbf{H}) \quad \forall \mathbf{V} \in H_{0}^{p}(\operatorname{curl}, \operatorname{div} 0, \Omega)\right\} .
\end{gathered}
$$

Here we note that we have

$$
\begin{aligned}
& I_{p}[\mathbf{V}]-I_{p}[\mathbf{H}]=\frac{1}{2} \\
& \quad \cdot \int_{\Omega}\left\{f_{p}\left(x,|\operatorname{curl} \mathbf{H}+\operatorname{curl}(\mathbf{V}-\mathbf{H})|^{2}\right)\right. \\
& \left.\quad-f_{p}\left(x,|\operatorname{curl} \mathbf{H}|^{2}\right)\right\} d x \\
& \geq \int_{\Omega} f_{p}^{\prime}\left(x,|\operatorname{curl} \mathbf{H}|^{2}\right) \operatorname{curl} \mathbf{H} \cdot \operatorname{curl}(\mathbf{V}-\mathbf{H}) d x .
\end{aligned}
$$

Next we will show that $\partial I_{p}[\mathbf{H}]$ for $\mathbf{H} \in D\left(\partial I_{p}\right)$ is singlevalued. In order to do so, define an operator $A_{p}$ by

$$
\begin{aligned}
& D\left(A_{p}\right)=\left\{\mathbf{H} \in H_{0}^{p}(\operatorname{curl}, \operatorname{div} 0, \Omega) ;\right. \\
& \left.\operatorname{curl}\left[f_{p}^{\prime}\left(x,|\operatorname{curl} \mathbf{H}|^{2}\right) \operatorname{curl} \mathbf{H}\right] \in L^{2}\left(\Omega, \mathbb{R}^{3}\right)\right\}, \\
& A_{p}[\mathbf{H}]=\operatorname{curl}\left[f_{p}^{\prime}\left(x,|\operatorname{curl} \mathbf{H}|^{2}\right) \operatorname{curl} \mathbf{H}\right] \\
& \text { for } \mathbf{H} \in D\left(A_{p}\right) .
\end{aligned}
$$

Since $\boldsymbol{\nu} \times(\mathbf{V}-\mathbf{H})=0$ on $\partial \Omega$, it follows from Lemma 5 and (33) that

$$
\begin{aligned}
I_{p}[\mathbf{V}]-I_{p}[\mathbf{H}] \geq\left(A_{p}[\mathbf{H}],\right. & \mathbf{V}-\mathbf{H}) \\
& \forall \mathbf{V} \in H_{0}^{p}(\operatorname{curl}, \operatorname{div} 0, \Omega) .
\end{aligned}
$$

This implies that $A_{p} \subset \partial I_{p}$; that is, $D\left(A_{p}\right) \subset D\left(\partial I_{p}\right)$ and $A_{p}[\mathbf{H}] \in \partial I_{p}[\mathbf{H}]$ for $\mathbf{H} \in D\left(A_{p}\right)$.

Lemma 8. Under the hypothesis (H.1), $\partial I_{p}$ is single-valued and $\partial I_{p}[\mathbf{H}]=\left\{A_{p}[\mathbf{H}]\right\}$.

Proof. We follow the arguments in Evans [11, page 571]. For any given $\mathbf{G} \in L^{2}\left(\Omega, \mathbb{R}^{3}\right)$, define a functional

$$
\begin{aligned}
J_{p} & {[\mathbf{V}] } \\
& =\int_{\Omega}\left(\frac{1}{2} f_{p}\left(x,|\operatorname{curl} \mathbf{V}|^{2}\right)+\frac{1}{2}|\mathbf{V}|^{2}-\mathbf{G} \cdot \mathbf{V}\right) d x
\end{aligned}
$$

on $H_{0}^{p}(\operatorname{curl}, \operatorname{div} 0, \Omega)$. We note that $H_{0}^{p}(\operatorname{curl}, \operatorname{div} 0, \Omega) \quad \subset$ $W^{1, p}\left(\Omega, \mathbb{R}^{3}\right)$ and $H_{0}^{p}(\operatorname{curl}, \operatorname{div} 0, \Omega)$ is a Banach space with respect to the norm $\|\operatorname{curl} \mathbf{V}\|_{L^{p}(\Omega)}$ which is equivalent to $W^{1, p}\left(\Omega, \mathbb{R}^{3}\right)$ norm according to the fact that $\Omega$ has no holes. 
We claim that $J_{p}$ has a minimizer in $H_{0}^{p}(\operatorname{curl}, \operatorname{div} 0, \Omega)$. In fact, for any $\varepsilon>0$, there exists a constant $C(\varepsilon, p)>0$ such that

$$
\begin{aligned}
J_{p}[\mathbf{V}] \geq & \frac{\lambda}{p} \int_{\Omega}|\operatorname{curl} \mathbf{V}|^{p} d x \\
& -\left\{\int_{\Omega}|\mathbf{G}|^{2} d x\right\}^{1 / 2}\left\{\int_{\Omega}|\mathbf{V}|^{2} d x\right\}^{1 / 2} \\
\geq & \frac{\lambda}{p} \int_{\Omega}|\operatorname{curl} \mathbf{V}|^{p} d x \\
& -\|\mathbf{G}\|_{L^{2}(\Omega)}\|\mathbf{V}\|_{L^{p}(\Omega)}|\Omega|^{(p-2) / 2 p} \\
\geq & \frac{\lambda}{p} \int_{\Omega}|\operatorname{curl} \mathbf{V}|^{p} d x-\varepsilon\|\mathbf{V}\|_{L^{p}(\Omega)}^{p} \\
& -C(\varepsilon, p)\|\mathbf{G}\|_{L^{2}(\Omega)}^{p /(p-1)} .
\end{aligned}
$$

Throughout this paper, $|\Omega|$ denotes the volume of $\Omega$. Therefore if we choose $\varepsilon>0$ small enough, we can see that $J_{p}$ is coercive. Since $K=H_{0}^{p}(\operatorname{curl}, \operatorname{div} 0, \Omega)$ is a closed convex subset of $W^{1, p}\left(\Omega, \mathbb{R}^{3}\right)$, if we show that $J_{p}: K \rightarrow \mathbb{R}$ is lower semicontinuous and convex, it follows that $J_{p}$ is weakly lower semicontinuous (cf. Takahashi [12, Lemma 1.3.9]). Since the convexity follows as before, we will show that $J_{p}$ is lower semicontinuous. Let $\mathbf{V}_{j} \rightarrow \mathbf{V}$ in $W^{1, p}\left(\Omega, \mathbb{R}^{3}\right)$ and $J_{p}\left[\mathbf{V}_{j}\right] \rightarrow$ $J$ as $j \rightarrow \infty$. Then curl $\mathbf{V}_{j} \rightarrow \operatorname{curl} \mathbf{V}$ in $L^{p}\left(\Omega, \mathbb{R}^{3}\right)$. Passing to a subsequence, we may assume that curl $\mathbf{V}_{j} \rightarrow \operatorname{curl} \mathbf{V}$ a.e. in $\Omega$. Since $f_{p}$ is a continuous function, $f_{p}\left(x,\left|\operatorname{curl} \mathbf{V}_{j}\right|^{2}\right) \rightarrow$ $f_{p}\left(x,|\operatorname{curl} \mathbf{V}|^{2}\right)$ a.e. in $\Omega$. Since $f_{p} \geq 0$, it follows from the Fatou lemma that

$$
\begin{aligned}
I_{p}[\mathbf{V}] & =\frac{1}{2} \int_{\Omega} f_{p}\left(x,|\operatorname{curl} \mathbf{V}|^{2}\right) d x \\
& \leq \liminf _{j \rightarrow \infty} \frac{1}{2} \int_{\Omega} f_{p}\left(x,\left|\operatorname{curl} \mathbf{V}_{j}\right|^{2}\right) d x \\
& =\liminf _{j \rightarrow \infty} I_{p}\left[\mathbf{V}_{j}\right]=I .
\end{aligned}
$$

From this fact and the fact that $\mathbf{V}_{j} \rightarrow \mathbf{V}$ in $L^{2}\left(\Omega, \mathbb{R}^{3}\right)$ since $p \geq 2$, we have $J_{p}[\mathbf{V}] \leq J$, so $J_{p}$ is weakly lower semicontinuous. Let $\left\{\mathbf{V}_{n}\right\} \subset H_{0}^{p}(\operatorname{curl}, \operatorname{div} 0, \Omega)$ be a minimizing sequence of $J_{p}$. Then

$$
J_{p}\left[\mathbf{V}_{n}\right]=\inf _{\mathbf{V} \in H_{0}^{p}(\operatorname{curl}, \operatorname{div} 0, \Omega)} J_{p}[\mathbf{V}]+o(1) \quad \text { as } n \longrightarrow \infty
$$

Since $J_{p}$ is coercive, $\left\{\mathbf{V}_{n}\right\}$ is bounded in $W^{1, p}\left(\Omega, \mathbb{R}^{3}\right)$. Passing to a subsequence, we may assume that $\mathbf{V}_{n} \rightarrow \mathbf{V}_{0}$ weakly in $W^{1, p}\left(\Omega, \mathbb{R}^{3}\right)$ and strongly in $L^{p}\left(\Omega, \mathbb{R}^{3}\right)$ by compactness of embedding from $W^{1, p}\left(\Omega, \mathbb{R}^{3}\right)$ to $L^{p}\left(\Omega, \mathbb{R}^{3}\right)$ as above. Since $\operatorname{div} \mathbf{V}_{n}=0$ in $\Omega$, we have $\operatorname{div} \mathbf{V}_{0}=0$ in $\Omega$, and since $\boldsymbol{\nu} \times \mathbf{V}_{n}=\mathbf{0}$ on $\partial \Omega$, we have $\boldsymbol{v} \times \mathbf{V}_{0}=\mathbf{0}$ on $\partial \Omega$. Thus we have $\mathbf{V}_{0} \in$ $H_{0}^{p}(\operatorname{curl}, \operatorname{div} 0, \Omega)$, and

$$
J_{p}\left[\mathbf{V}_{0}\right] \leq \liminf _{n \rightarrow \infty} J_{p}\left[\mathbf{V}_{n}\right]=\inf _{\mathbf{V} \in H_{0}^{p}(\operatorname{curl}, \operatorname{div} 0, \Omega)} J_{p}[\mathbf{V}] .
$$

Thus a minimizer exists. So let $\mathbf{H} \in H_{0}^{p}(\operatorname{curl}, \operatorname{div} 0, \Omega)$ be a minimizer of $J_{p}$. Then $\mathbf{H}$ satisfies the Euler-Lagrange equation weakly:

$$
\mathbf{H}+\operatorname{curl}\left[f_{p}^{\prime}\left(x,|\operatorname{curl} \mathbf{H}|^{2}\right) \operatorname{curl} \mathbf{H}\right]=\mathbf{G} .
$$

Since $\mathbf{H}, \mathbf{G} \in L^{2}\left(\Omega, \mathbb{R}^{3}\right)$, we have

$$
\operatorname{curl}\left[f_{p}^{\prime}\left(x,|\operatorname{curl} \mathbf{H}|^{2}\right) \operatorname{curl} \mathbf{H}\right] \in L^{2}\left(\Omega, \mathbb{R}^{3}\right),
$$

and so $\mathbf{H} \in D\left(A_{p}\right)$ and $\mathbf{H}+A_{p}[\mathbf{H}]=\mathbf{G}$. Since $\mathbf{G} \in L^{2}\left(\Omega, \mathbb{R}^{3}\right)$ is arbitrary, we have

$$
R\left(I+A_{p}\right)=L^{2}\left(\Omega, \mathbb{R}^{3}\right)
$$

where $R\left(I+A_{p}\right)$ denotes the range of $I+A_{p}$.

We show that $A_{p}=\partial I_{p}$. For any $\mathbf{V} \in D\left(\partial I_{p}\right)$ and $\mathbf{W} \in$ $\partial I_{p}[\mathbf{V}]$, there exists $\mathbf{H} \in D\left(A_{p}\right)$ such that $\mathbf{H}+A_{p}[\mathbf{H}]=\mathbf{V}+$ W. Since $A_{p}[\mathbf{H}] \in \partial I_{p}[\mathbf{H}]$, we see that $\mathbf{H}+\partial I_{p}[\mathbf{H}] \ni \mathbf{V}+$ $\mathbf{W}$. On the other hand, $\mathbf{V}+\partial I_{p}[\mathbf{V}] \ni \mathbf{V}+\mathbf{W}$. According to [11, Chapter 9, Section 6, Theorem 1(iv)], the equation $\mathbf{H}+$ $\partial I_{p}[\mathbf{H}] \ni \mathbf{V}+\mathbf{W}$ has a unique solution in $D\left(\partial I_{p}\right)$. Thus we have $\mathbf{V}=\mathbf{H} \in D\left(\partial I_{p}\right)$ and $A_{p}[\mathbf{H}]=\mathbf{W}$. Hence $\partial I_{p}$ is singlevalued and $\partial I_{p}[\mathbf{H}]=\left\{A_{p}[\mathbf{H}]\right\}$. This completes the proof.

If $\mathbf{F}=\mathbf{F}(x, t)$ and $\mathbf{H}_{0}=\mathbf{H}_{0}(x)$ satisfy (H.2), it follows from [9, Theorems 3.6 and 3.4] that the system

$$
\begin{aligned}
\mathbf{H}_{t}+\partial I_{p}[\mathbf{H}] & \ni \mathbf{F} \quad \text { in } Q_{T}, \\
\mathbf{H}(x, 0) & =\mathbf{H}_{0}(x) \quad x \in \Omega
\end{aligned}
$$

has a unique solution $\mathbf{H}$ in the sense of Definition 4. Taking Lemma 8 into consideration, we can see that $\mathbf{H}$ is a unique solution of system (16)-(19).

Proof of Theorem 6. Let $\mathbf{H}$ be a solution of (16)-(19). Taking the inner product of (16) and $\mathbf{H}$ and then integrating over $Q_{t}=\Omega \times[0, t]$, we have

$$
\begin{aligned}
& \iint_{Q_{t}} \mathbf{H}_{\tau} \cdot \mathbf{H} d x d \tau \\
& \quad+\iint_{Q_{t}} \operatorname{curl}\left[f_{p}^{\prime}\left(x,|\operatorname{curl} \mathbf{H}|^{2}\right) \operatorname{curl} \mathbf{H}\right] \cdot \mathbf{H} d x d \tau \\
& \quad=\iint_{Q_{t}} \mathbf{F} \cdot \mathbf{H} d x d \tau .
\end{aligned}
$$

The first term of left hand side of (45) is equal to

$$
\begin{aligned}
& \frac{1}{2} \iint_{\mathrm{Q}_{t}} \frac{d}{d \tau}|\mathbf{H}(x, \tau)|^{2} d x d \tau \\
& \quad=\frac{1}{2} \int_{\Omega}|\mathbf{H}(x, t)|^{2} d x-\frac{1}{2} \int_{\Omega}\left|\mathbf{H}_{0}(x)\right|^{2} d x .
\end{aligned}
$$


Since $\boldsymbol{v} \times \mathbf{H}(x, t)=\mathbf{0}$ on $\partial \Omega \times[0, t]$, using Lemma 5 and (H.1), the second term of left hand side of (45) satisfies

$$
\begin{aligned}
& \iint_{Q_{t}} \operatorname{curl}\left[f_{p}^{\prime}\left(x,|\operatorname{curl} \mathbf{H}|^{2}\right) \operatorname{curl} \mathbf{H}\right] \cdot \mathbf{H} d x d \tau \\
& \quad=\iint_{Q_{t}} f_{p}^{\prime}\left(x,|\operatorname{curl} \mathbf{H}|^{2}\right)|\operatorname{curl} \mathbf{H}|^{2} d x d \tau \\
& \quad \geq \lambda \iint_{Q_{t}}|\operatorname{curl} \mathbf{H}|^{p} d x d \tau .
\end{aligned}
$$

Applying the Schwarz inequality, the right hand side of (45) satisfies that, for any $\varepsilon>0$, there exists a constant $C(\varepsilon)$,

$$
\begin{aligned}
\iint_{Q_{t}} \mathbf{F} \cdot \mathbf{H} d x d \tau \leq & \varepsilon \iint_{Q_{t}}|\mathbf{H}|^{2} d x d \tau \\
& +C(\varepsilon) \iint_{Q_{t}}|\mathbf{F}|^{2} d x d \tau \\
\leq & \varepsilon T \sup _{t \in[0, T]} \int_{\Omega}|\mathbf{H}(x, t)|^{2} d x \\
& +C(\varepsilon) \iint_{Q_{T}}|\mathbf{F}|^{2} d x d t .
\end{aligned}
$$

Thus we have

$$
\begin{aligned}
& \frac{1}{2} \int_{\Omega}|\mathbf{H}(x, t)|^{2} d x+\lambda \iint_{Q_{t}}|\operatorname{curl} \mathbf{H}|^{2} d x d \tau \\
& \leq \frac{1}{2} \int_{\Omega}\left|\mathbf{H}_{0}(x)\right|^{2} d x+\varepsilon T \sup _{t \in[0, T]} \int_{\Omega}|\mathbf{H}(x, t)|^{2} d x \\
& \quad+C(\varepsilon) \iint_{Q_{T}}|\mathbf{F}|^{2} d x d t
\end{aligned}
$$

for any $t \in[0, T]$. Taking the supremum on $[0, T]$ and then choosing $\varepsilon>0$ small enough, there exists a constant $C$ depending on $T$, but independent of $p$ such that

$$
\begin{aligned}
& \sup _{t \in[0, T]} \int_{\Omega}|\mathbf{H}(x, t)|^{2} d x+\iint_{Q_{T}}|\operatorname{curl} \mathbf{H}|^{p} d x d t \\
& \quad \leq C\left[\int_{\Omega}\left|\mathbf{H}_{0}(x)\right|^{2} d x+\iint_{Q_{T}}|\mathbf{F}(x, t)|^{2} d x d t\right] .
\end{aligned}
$$

Next, taking the inner product of (16) and $\mathbf{H}_{t}$ and integrating over $Q_{t}$, we have, using Lemma 5,

$$
\begin{aligned}
& \iint_{Q_{t}}\left|\mathbf{H}_{\tau}\right|^{2} d x d \tau \\
& \quad+\iint_{Q_{t}} f_{p}^{\prime}\left(x,|\operatorname{curl} \mathbf{H}|^{2}\right) \operatorname{curl} \mathbf{H} \cdot \operatorname{curl} \mathbf{H}_{\tau} d x d \tau \\
& \quad=\iint_{Q_{t}} \mathbf{F} \cdot \mathbf{H}_{\tau} d x d \tau .
\end{aligned}
$$

If we note that

$$
\begin{aligned}
\frac{d}{d \tau} f_{p}\left(x,|\operatorname{curl} \mathbf{H}(x, \tau)|^{2}\right) \\
=2 f_{s}^{\prime}\left(x,|\operatorname{curl} \mathbf{H}(x, \tau)|^{2}\right) \operatorname{curl} \mathbf{H}(x, \tau) \\
\quad \cdot \operatorname{curl}_{\tau}(x, \tau)
\end{aligned}
$$

it is shown that

$$
\begin{gathered}
\iint_{\mathrm{Q}_{t}} f_{p}^{\prime}\left(x,|\operatorname{curl} \mathbf{H}|^{2}\right) \operatorname{curl} \mathbf{H} \cdot \operatorname{curl} \mathbf{H}_{\tau} d x d \tau \\
=\frac{1}{2} \iint_{\mathrm{Q}_{t}} \frac{d}{d \tau} f_{p}\left(x,|\operatorname{curl} \mathbf{H}(x, \tau)|^{2}\right) d x d \tau \\
=\frac{1}{2} \int_{\Omega} f_{p}\left(x,|\operatorname{curl} \mathbf{H}(x, t)|^{2}\right) d x \\
-\frac{1}{2} \int_{\Omega} f_{p}\left(x,\left|\operatorname{curl} \mathbf{H}_{0}(x)\right|^{2}\right) d x .
\end{gathered}
$$

It follows from (H.1) that

$$
\begin{aligned}
& \iint_{Q_{t}}\left|\mathbf{H}_{\tau}\right|^{2} d x d \tau+\frac{\lambda}{p} \int_{\Omega}|\operatorname{curl} \mathbf{H}(x, t)|^{p} d x \\
& \leq \frac{\Lambda}{p} \int_{\Omega}\left|\operatorname{curl} \mathbf{H}_{0}(x)\right|^{p} d x+\iint_{Q_{t}} \mathbf{F} \cdot \mathbf{H}_{\tau} d x d \tau \\
& \leq \frac{\Lambda}{p} \int_{\Omega}\left|\operatorname{curl} \mathbf{H}_{0}(x)\right|^{p} d x+\frac{1}{2} \iint_{Q_{t}}\left|\mathbf{H}_{\tau}\right|^{2} d x d \tau \\
& \quad+4 \iint_{Q_{t}}|\mathbf{F}|^{2} d x d \tau .
\end{aligned}
$$

Thus we have

$$
\begin{aligned}
& \frac{1}{2} \iint_{Q_{t}}\left|\mathbf{H}_{\tau}\right|^{2} d x d \tau+\frac{\lambda}{p} \int_{\Omega}|\operatorname{curl} \mathbf{H}(x, t)|^{p} d x \\
& \quad \leq \frac{\Lambda}{p} \int_{\Omega}\left|\operatorname{curl} \mathbf{H}_{0}(x)\right|^{p} d x+4 \iint_{Q_{T}}|\mathbf{F}|^{2} d x d t .
\end{aligned}
$$

Taking the supremum of the left hand side, there exists a constant $C$ independent of $p$ such that

$$
\begin{aligned}
& \frac{1}{2} \iint_{Q_{T}}\left|\mathbf{H}_{t}\right|^{2} d x d t+\frac{\lambda}{p_{t \in[0, T]}} \sup _{\Omega}|\operatorname{curl} \mathbf{H}(x, t)|^{p} d x \\
& \quad \leq C\left[\frac{1}{p} \int_{\Omega}\left|\operatorname{curl} \mathbf{H}_{0}(x)\right|^{p} d x+\iint_{Q_{T}}|\mathbf{F}|^{2} d x d t\right],
\end{aligned}
$$

where the constant $C$ is independent of $p$. It follows from this inequality that we can see that $\mathbf{H}_{t} \in L^{2}\left(Q_{T}\right)$ and $\mathbf{H} \in L^{\infty}\left(0, T ; H_{0}^{p}(\operatorname{curl}, \operatorname{div} 0, \Omega)\right)$. This completes the proof of Theorem 6 .

For more regularity of solution, we assume the following.

(H.3) F $\in L^{\infty}\left(0, T ; L^{2}(\Omega)\right)$, curl F $\in L^{\infty}\left(0, T ; L^{p}(\Omega)\right)$, curl $\mathbf{F}_{t} \in L^{p}\left(Q_{T}\right)$, and $\mathbf{F}$ has a compact support in $\Omega$ for every $t \in[0, T]$. 
Then we have the following.

Theorem 9. Under (H.1)-(H.3), the solution $\mathbf{H}=\mathbf{H}(x, t)$ of (16)-(19) satisfies $\mathbf{H}_{t} \in L^{\infty}\left(0, T ; L^{2}(\Omega)\right)$ and

$$
\operatorname{curl}\left[f_{p}^{\prime}\left(x,|\operatorname{curl} \mathbf{H}|^{2}\right) \operatorname{curl} \mathbf{H}\right] \in L^{2}\left(0, T ; L^{2}(\Omega)\right) .
$$

Moreover, the following estimates hold:

$$
\begin{aligned}
& \sup _{t \in[0, T]} \int_{\Omega}|\operatorname{curl} \mathbf{H}|^{p} d x \\
& +\iint_{Q_{T}}\left|\operatorname{curl}\left[f_{p}^{\prime}\left(x,|\operatorname{curl} \mathbf{H}|^{2}\right) \operatorname{curl} \mathbf{H}\right]\right|^{2} d x d t \\
& \quad \leq C\left[\int_{\Omega}\left|\operatorname{curl} \mathbf{H}_{0}\right|^{p} d x+\iint_{\mathrm{Q}_{T}}|\operatorname{curl} \mathbf{F}|^{p} d x d t\right] \\
& \iint_{Q_{T}}\left\{|\operatorname{curl} \mathbf{H}|^{p-2}\left|\operatorname{curl} \mathbf{H}_{t}\right|^{2}+f_{p}^{\prime \prime}\left(x,|\operatorname{curl} \mathbf{H}|^{2}\right)\right. \\
& \left.\quad \cdot\left(\operatorname{curl} \mathbf{H} \cdot \operatorname{curl} \mathbf{H}_{t}\right)^{2}\right\} d x d t \\
& \quad+\sup _{t \in[0, T]} \int_{\Omega}\left|\operatorname{curl}\left[f_{p}^{\prime}\left(x,|\operatorname{curl} \mathbf{H}|^{2}\right) \operatorname{curl} \mathbf{H}\right]\right|^{2} d x \\
& \quad+\sup _{t \in[0, T]} \int_{\Omega}\left|\mathbf{H}_{t}\right|^{2} d x \\
& \quad \leq C\left[\int_{\Omega}\left|\operatorname{curl}\left[f_{p}^{\prime}\left(x,\left|\operatorname{curl} \mathbf{H}_{0}\right|^{2}\right) \operatorname{curl} \mathbf{H}_{0}\right]\right|^{2}\right. \\
& \left.\quad+\sup _{t \in[0, T]} \int_{\Omega}|\operatorname{curl} \mathbf{F}|^{p} d x+\sup _{t \in[0, T]} \int_{\Omega}|\mathbf{F}|^{2} d x\right] \\
& \quad+\left.\operatorname{curl} \mathbf{F}_{t}\right|^{p} d x d t+\int_{Q_{T}}\left|\operatorname{curl} \mathbf{H}_{0}\right|^{p} d x
\end{aligned}
$$

where the constant $C$ depends on $T$ and $p$.

Proof. For the brevity of notation, we write $\mathbf{V}=$ curl H. Taking curl of (16), we have

$$
\mathbf{V}_{t}+\operatorname{curl}^{2}\left[f_{p}^{\prime}\left(x,|\mathbf{V}|^{2}\right) \mathbf{V}\right]=\operatorname{curl} \mathbf{F}
$$

Since $\boldsymbol{\nu} \times \mathbf{H}(x, t)=\mathbf{0}$ on $\partial \Omega \times[0, T]$, we have $\boldsymbol{\nu} \times \mathbf{H}_{t}(x, t)=\mathbf{0}$ on $\partial \Omega \times[0, T]$. Since $\mathbf{F}=\mathbf{0}$ near $\partial \Omega$ for every $t \in[0, T]$, it follows from (16) that

$$
\boldsymbol{v} \times \operatorname{curl}\left[f_{p}^{\prime}\left(x,|\mathbf{V}|^{2}\right) \mathbf{V}\right]=\mathbf{0} \quad \text { on } \partial \Omega \times[0, T] .
$$

Moreover we have

$$
\begin{aligned}
\mathbf{V}_{t} \cdot f_{p}^{\prime}\left(x,|\mathbf{V}|^{2}\right) \mathbf{V} & =\frac{1}{2} f_{p}^{\prime}\left(x,|\mathbf{V}|^{2}\right) \frac{d}{d t}|\mathbf{V}|^{2} \\
& =\frac{1}{2} \frac{d}{d t} f_{p}\left(x,|\mathbf{V}|^{2}\right)
\end{aligned}
$$

Taking the inner product of $(60)$ and $f_{p}^{\prime}\left(x,|\mathbf{V}|^{2}\right) \mathbf{V}$ and then integrating over $Q_{t}(0 \leq t \leq T)$, it follows from (61) and (62) that

$$
\begin{aligned}
& \frac{1}{2} \iint_{Q_{t}} \frac{d}{d \tau} f_{p}\left(x,|\mathbf{V}|^{2}\right) d x d \tau \\
& \quad+\iint_{Q_{t}}\left|\operatorname{curl}\left[f_{p}^{\prime}\left(x,|\mathbf{V}|^{2}\right) \mathbf{V}\right]\right|^{2} d x d \tau \\
& \quad=\iint_{Q_{t}} \operatorname{curl} \mathbf{F} \cdot f_{p}^{\prime}\left(x,|\mathbf{V}|^{2}\right) \mathbf{V} d x d \tau .
\end{aligned}
$$

Therefore using the Hölder inequality, for any $\varepsilon>0$, there exists $C(\varepsilon)>0$ such that

$$
\begin{aligned}
& \frac{1}{2} \int_{\Omega} f_{p}\left(x,|\mathbf{V}(x, t)|^{2}\right) d x \\
& \quad-\frac{1}{2} \int_{\Omega} f_{p}\left(x,|\mathbf{V}(x, 0)|^{2}\right) d x \\
& \quad+\iint_{Q_{t}}\left|\operatorname{curl}\left[f_{p}^{\prime}\left(x,|\mathbf{V}|^{2}\right) \mathbf{V}\right]\right|^{2} d x d \tau \\
& \leq \varepsilon \\
& \quad \iint_{Q_{t}}\left|f_{p}^{\prime}\left(x,|\mathbf{V}|^{2}\right) \mathbf{V}\right|^{p^{\prime}} d x d \tau \\
& \quad+C(\varepsilon) \iint_{Q_{t}}|\operatorname{curl} \mathbf{F}|^{p} d x d \tau
\end{aligned}
$$

Since $\left(f_{p}^{\prime}\left(x, s^{2}\right) s\right)^{p^{\prime}} \leq\left(\Lambda s^{p-1}\right)^{p^{\prime}} \leq \Lambda^{p^{\prime}} s^{p} \leq \Lambda^{p^{\prime}}(p / 2 \lambda) f_{p}(x$, $\left.s^{2}\right)$ for $s \geq 0$, the first term of the right hand side of (64) is estimated by

$$
\varepsilon \Lambda^{p^{\prime}} \frac{p}{2 \lambda} \iint_{Q_{t}} f_{p}\left(x,|\mathbf{V}|^{2}\right) d x d \tau .
$$

Thus we have

$$
\begin{aligned}
& \frac{1}{2} \int_{\Omega} f_{p}\left(x,|\mathbf{V}(x, t)|^{2}\right) d x \\
& \quad+\iint_{Q_{t}}\left|\operatorname{curl}\left[f_{p}^{\prime}\left(x,|\mathbf{V}|^{2}\right) \mathbf{V}\right]\right|^{2} d x d \tau \\
& \leq \frac{1}{2} \int_{\Omega} f_{p}\left(x,|\mathbf{V}(x, 0)|^{2}\right) d x \\
& \quad+\varepsilon \Lambda^{p^{\prime}} \frac{p}{2 \lambda} T \sup _{t \in[0, T]} \int_{\Omega} f_{p}\left(x,|\mathbf{V}(x, t)|^{2}\right) d x \\
& \quad+C(\varepsilon) \iint_{Q_{T}}|\operatorname{curl} \mathbf{F}|^{p} d x d t .
\end{aligned}
$$

Taking the supremum of the left hand side and then choosing $\varepsilon>0$ small enough, we have

$$
\begin{aligned}
& \sup _{t \in[0, T]} \int_{\Omega} f_{p}\left(x,|\mathbf{V}(x, t)|^{2}\right) d x \\
& \quad+\iint_{Q_{T}}\left|\operatorname{curl}\left[f_{p}^{\prime}\left(x,|\mathbf{V}|^{2}\right) \mathbf{V}\right]\right|^{2} d x d t
\end{aligned}
$$




$$
\begin{aligned}
& \leq C\left[\int_{\Omega} f_{p}\left(x,|\mathbf{V}(x, 0)|^{2}\right) d x\right. \\
& \left.+\iint_{Q_{T}}|\operatorname{curl} \mathbf{F}|^{p} d x d t\right],
\end{aligned}
$$

where the constant $C$ depends on $p, T$, and $\varepsilon$. Since $(2 \lambda / p) s^{p} \leq f_{p}\left(x, s^{2}\right) \leq(2 \Lambda / p) s^{p}$ for $s \geq 0$, we can get the first estimate (58).

Next we show the second estimate (59). Taking the inner product of $(60)$ and $\left(f_{p}^{\prime}\left(x,|\mathbf{V}|^{2}\right) \mathbf{V}\right)_{t}$ and then integrating over $Q_{t}$, we have

$$
\begin{aligned}
& \iint_{Q_{t}} \mathbf{V}_{\tau} \cdot\left(f_{p}^{\prime}\left(x,|\mathbf{V}|^{2}\right) \mathbf{V}\right)_{\tau} d x d \tau \\
& \quad+\iint_{Q_{t}} \operatorname{curl}\left[f_{p}^{\prime}\left(x,|\mathbf{V}|^{2}\right) \mathbf{V}\right] \\
& \quad \cdot\left(\operatorname{curl}\left[f_{p}^{\prime}\left(x,|\mathbf{V}|^{2}\right) \mathbf{V}\right]\right)_{\tau} d x d \tau \\
& \quad=\iint_{Q_{t}} \operatorname{curl} \mathbf{F} \cdot\left(f_{p}^{\prime}\left(x,|\mathbf{V}|^{2}\right) \mathbf{V}\right)_{\tau} d x d \tau
\end{aligned}
$$

The first term of the left hand side of (68) is estimated as follows:

$$
\begin{aligned}
& \iint_{Q_{t}}\left\{\left|\mathbf{V}_{\tau}\right|^{2} f_{p}^{\prime}\left(x,|\mathbf{V}|^{2}\right)\right. \\
& \left.\quad+2 f_{p}^{\prime \prime}\left(x,|\mathbf{V}|^{2}\right)\left(\mathbf{V} \cdot \mathbf{V}_{\tau}\right)^{2}\right\} d x d \tau \\
& \quad \geq \iint_{Q_{t}}\left\{\lambda|\mathbf{V}|^{p-2}\left|\mathbf{V}_{\tau}\right|^{2}\right. \\
& \left.\quad+2 f_{p}^{\prime \prime}\left(x,|\mathbf{V}|^{2}\right)\left(\mathbf{V} \cdot \mathbf{V}_{\tau}\right)^{2}\right\} d x d \tau .
\end{aligned}
$$

Here we note that $f_{p}^{\prime \prime} \geq 0$. The second term of the left hand side of (68) is equal to

$$
\begin{aligned}
\frac{1}{2} \iint_{Q_{t}} \frac{d}{d \tau}\left|\operatorname{curl}\left[f_{p}^{\prime}\left(x,|\mathbf{V}|^{2}\right) \mathbf{V}\right]\right|^{2} d x d \tau \\
=\frac{1}{2} \int_{\Omega}\left|\operatorname{curl}\left[f_{p}^{\prime}\left(x,|\mathbf{V}(x, t)|^{2}\right) \mathbf{V}(x, t)\right]\right|^{2} d x \\
\quad-\frac{1}{2} \int_{\Omega}\left|\operatorname{curl}\left[f_{p}^{\prime}\left(x,|\mathbf{V}(x, 0)|^{2}\right) \mathbf{V}(x, 0)\right]\right|^{2} d x .
\end{aligned}
$$

For the estimate of the right hand side of (68), using the integration by parts and taking (H.1) into consideration, we have

$$
\begin{aligned}
& \iint_{Q_{t}} \operatorname{curl} \mathbf{F} \cdot\left(f_{p}^{\prime}\left(x,|\mathbf{V}|^{2}\right) \mathbf{V}\right)_{\tau} d x d \tau \\
& =-\iint_{Q_{t}} \operatorname{curl} \mathbf{F}_{\tau} \cdot f_{p}^{\prime}\left(x,|\mathbf{V}|^{2}\right) \mathbf{V} d x d \tau \\
& \quad+\left[\int_{\Omega} \operatorname{curl} \mathbf{F} \cdot f_{p}^{\prime}\left(x,|\mathbf{V}|^{2}\right) \mathbf{V} d x\right]_{\tau=0}^{\tau=t} \\
& \leq C \iint_{Q_{t}}\left|\operatorname{curl} \mathbf{F}_{\tau}\right|^{p} d x d \tau
\end{aligned}
$$

$$
\begin{aligned}
& +C \iint_{Q_{t}}\left|f_{p}^{\prime}\left(x,|\mathbf{V}|^{2}\right) \mathbf{V}\right|^{p^{\prime}} d x d \tau \\
& +C \sup _{t \in[0, T]} \int_{\Omega}|\operatorname{curl} \mathbf{F}|^{p} d x \\
& +C \sup _{t \in[0, T]} \int_{\Omega}\left|f_{p}^{\prime}\left(x,|\mathbf{V}|^{2}\right) \mathbf{V}\right|^{p^{\prime}} d x \\
& \leq C \iint_{Q_{t}}\left|\operatorname{curl} \mathbf{F}_{\tau}\right|^{p} d x d \tau+C \sup _{t \in[0, T]} \int_{\Omega}|\operatorname{curl} \mathbf{F}|^{p} d x \\
& +C \sup _{t \in[0, T]} \int_{\Omega}|\mathbf{V}|^{p} d x .
\end{aligned}
$$

Here the constant $C$ depends on $T$ and $p$. By the first inequality (58), there exists a constant $C$ depending on $T$ and $p$ such that

$$
\begin{aligned}
& \sup _{t \in[0, T]} \int_{\Omega}|\mathbf{V}|^{p} d x \\
& \quad \leq C\left[\int_{\Omega}\left|\operatorname{curl} \mathbf{H}_{0}\right|^{p} d x+T \sup _{t \in[0, T]} \int_{\Omega}|\operatorname{curl} \mathbf{F}|^{p} d x\right] .
\end{aligned}
$$

Adding the above inequalities, we get second inequality (59) without the term

$$
\sup _{t \in[0, T]} \int_{\Omega}\left|\mathbf{H}_{t}\right|^{2} d x
$$

which we now estimate the term (73). From (16), we get

$$
\begin{aligned}
& \sup _{t \in[0, T]} \int_{\Omega}\left|\mathbf{H}_{t}\right|^{2} d x \\
& \leq 2 \sup _{t \in[0, T]} \int_{\Omega}\left|\operatorname{curl}\left[f_{p}^{\prime}\left(x,|\operatorname{curl} \mathbf{H}|^{2}\right) \operatorname{curl} \mathbf{H}\right]\right|^{2} d x \\
& \quad+2 \sup _{t \in[0, T]} \int_{\Omega}|\mathbf{F}|^{2} d x .
\end{aligned}
$$

The first term of the right hand side of this inequality is already estimated in (58). This completes the proof of Theorem 9.

By Lemma 2, we have the following.

Theorem 10. Under (H.1)-(H.3), let $\mathbf{H}=\mathbf{H}(x, t)$ be a solution of (16)-(19). Then the following hold.

(i) $\mathbf{H} \in L^{\infty}\left(0, T ; L^{3 p /(3-p)}(\Omega)\right)$ if $2 \leq p<3$.

(ii) $\mathbf{H} \in L^{\infty}\left(0, T ; L^{q}(\Omega)\right)$ for any $1<q<\infty$ if $p=3$.

(iii) $\mathbf{H} \in C^{\alpha, \beta}\left(\overline{Q_{T}}\right)$ if $p>3$ where $\alpha=1-3 / p$ and $\beta=$ $\min \{\alpha / 2,1 / 4\}$.

Proof. By Theorem $6, \mathbf{H} \in L^{\infty}\left(0, T ; W^{1, p}(\Omega)\right)$. Using the Sobolev embedding theorem, (i) and (ii) are clear. Similarly if $p>3, \mathbf{H}(x, t)$ is Hölder continuous with respect to $x$ 
with the Hölder exponent $\alpha=1-3 / p$. We will show that $\mathbf{H}(x, t)$ is Hölder continuous with respect to $t$ with the Hölder exponent $\beta$. Let $t_{1}, t_{2} \in[0, T], 0<t_{2}-t_{1}$ small and $x_{0} \in \bar{\Omega}$, and define $B_{r}=B_{r}\left(x_{0}\right)$ a ball in $\Omega$ centered at $x_{0}$ with radius $r=\left(t_{2}-t_{1}\right)^{1 / 2}$. If $B_{r} \not \subset \Omega$, we consider $B_{r} \cap \bar{\Omega}$ in the following. From Schwarz's inequality, we have

$$
\begin{aligned}
& \int_{B_{r}}\left|\mathbf{H}\left(x, t_{2}\right)-\mathbf{H}\left(x, t_{1}\right)\right|^{2} d x \\
& \quad=\int_{B_{r}}\left|\int_{t_{1}}^{t_{2}} \mathbf{H}_{t}(x, t) d t\right|^{2} d x \\
& \quad \leq \int_{B_{r}} \int_{t_{1}}^{t_{2}}\left|\mathbf{H}_{t}(x, t)\right|^{2} d t d x\left(t_{2}-t_{1}\right) \\
& \leq\left\|\mathbf{H}_{t}\right\|_{L^{\infty}\left(0, T ; L^{2}(\Omega)\right)}^{2}\left(t_{2}-t_{1}\right)^{2}=C\left(t_{2}-t_{1}\right)^{2},
\end{aligned}
$$

where the constant $C$ is independent of $x$. By the mean value theorem for integral, there exists $x^{*} \in B_{r}$ such that

$$
\begin{aligned}
& \left|\mathbf{H}\left(x^{*}, t_{2}\right)-\mathbf{H}\left(x^{*}, t_{1}\right)\right|^{2}\left|B_{r}\right| \\
& \quad=\int_{B_{r}}\left|\mathbf{H}\left(x, t_{2}\right)-\mathbf{H}\left(x, t_{1}\right)\right|^{2} d x \leq C\left(t_{2}-t_{1}\right)^{2} .
\end{aligned}
$$

Therefore we have

$$
\begin{aligned}
& \left|\mathbf{H}\left(x^{*}, t_{2}\right)-\mathbf{H}\left(x^{*}, t_{1}\right)\right| \leq C r^{-3 / 2}\left(t_{2}-t_{1}\right) \\
& \quad \leq C\left(t_{2}-t_{1}\right)^{1 / 4} .
\end{aligned}
$$

Thus for any $x \in B_{r}$,

$$
\begin{aligned}
\left|\mathbf{H}\left(x, t_{2}\right)-\mathbf{H}\left(x, t_{1}\right)\right| \leq & \left|\mathbf{H}\left(x, t_{2}\right)-\mathbf{H}\left(x^{*}, t_{2}\right)\right| \\
& +\left|\mathbf{H}\left(x^{*}, t_{2}\right)-\mathbf{H}\left(x^{*}, t_{1}\right)\right| \\
& +\left|\mathbf{H}\left(x^{*}, t_{1}\right)-\mathbf{H}\left(x, t_{1}\right)\right| \\
\leq & C\left|x-x^{*}\right|^{\alpha}+C\left(t_{2}-t_{1}\right)^{1 / 4} \\
\leq & C\left(t_{2}-t_{1}\right)^{\alpha / 2}+C\left(t_{2}-t_{1}\right)^{1 / 4} \\
\leq & C\left(t_{2}-t_{1}\right)^{\beta} .
\end{aligned}
$$

\section{Limit Solution as $p \rightarrow \infty$}

In this section, we consider the asymptotic behavior of the solution $\mathbf{H}=\mathbf{H}(x, t)$ (depending on $p$ ) as $p \rightarrow \infty$. We assume the following.

(H.4) One has $\left\|\operatorname{curl} \mathbf{H}_{0}\right\|_{L^{\infty}(\Omega)} \leq 1$.

Define a subspace $K=H_{0}^{2}(\operatorname{curl}, \operatorname{div} 0, \Omega)$ of $L^{2}\left(\Omega, \mathbb{R}^{3}\right)$. For $\mathbf{V} \in L^{2}\left(\Omega, \mathbb{R}^{3}\right)$, define a functional

$$
I_{\infty}[\mathbf{V}]= \begin{cases}0 & \text { if } \mathbf{V} \in K,|\operatorname{curl} \mathbf{V}| \leq 1 \text { a.e. in } \Omega, \\ +\infty & \text { otherwise. }\end{cases}
$$

It is clear that $I_{\infty}$ is proper convex functional. We will show that $I_{\infty}$ is lower semicontinuous. Let $\mathbf{V}_{n}, \mathbf{V} \in L^{2}\left(\Omega, \mathbb{R}^{3}\right)$, $\mathbf{V}_{n} \rightarrow \mathbf{V}$ in $L^{2}\left(\Omega, \mathbb{R}^{3}\right)$, and $\lim _{n \rightarrow \infty} I_{\infty}\left[\mathbf{V}_{n}\right]=I$. Then it suffices to show that $I_{\infty}[\mathbf{V}] \leq I$. If $I=\infty$, then it is trivial, so we may assume that $I<\infty$, and passing to a subsequence, we may assume that $I_{\infty}\left[\mathbf{V}_{n}\right]<\infty$. Thus $I_{\infty}\left[\mathbf{V}_{n}\right]=0$, and $\mid$ curl $\mathbf{V}_{n} \mid \leq 1$. Since $\Omega$ has no holes, it follows from [7] that

$$
\begin{aligned}
& \left\|\mathbf{V}_{n}\right\|_{W^{1,2}(\Omega)} \leq C\left(\left\|\operatorname{div} \mathbf{V}_{n}\right\|_{L^{2}(\Omega)}+\left\|\operatorname{curl} \mathbf{V}_{n}\right\|_{L^{2}(\Omega)}\right. \\
& \left.\quad+\left\|\boldsymbol{\nu} \times \mathbf{V}_{n}\right\|_{W^{1 / 2,2}(\partial \Omega)}\right) \leq C\left\|\operatorname{curl} \mathbf{V}_{n}\right\|_{L^{2}(\Omega)} \leq C|\Omega| .
\end{aligned}
$$

Therefore $\left\{\mathbf{V}_{n}\right\}$ is bounded in $W^{1,2}\left(\Omega, \mathbb{R}^{3}\right)$. Passing to a subsequence, we may assume that $\mathbf{V} \rightarrow \widetilde{\mathbf{V}}$ weakly in $W^{1,2}(\Omega$, $\left.\mathbb{R}^{3}\right)$ and strongly in $L^{2}\left(\Omega, \mathbb{R}^{3}\right)$. Thus we see that $\widetilde{\mathbf{V}}=\mathbf{V}$. Since it is clear that $\operatorname{div} \mathbf{V}=0$ in $\Omega$ and $\boldsymbol{v} \times \mathbf{V}=\mathbf{0}$ on $\partial \Omega$, it suffices to prove $\mid$ curl $\mathbf{V} \mid \leq 1$ a.e. in $\Omega$, in order to show that $\mathbf{V} \in D\left(I_{\infty}\right)$. For any $\delta>0$, define a set

$$
A_{\delta}=\{x \in \Omega ;|\operatorname{curl} \mathbf{V}(x)| \geq 1+\delta\}
$$

Since curl $\mathbf{V}_{n} \rightarrow$ curl $\mathbf{V}$ weakly in $L^{2}\left(A_{\delta}, \mathbb{R}^{3}\right)$, we have

$$
\begin{aligned}
(1+\delta)^{2}\left|A_{\delta}\right| & \leq \int_{A_{\delta}}|\operatorname{curl} \mathbf{V}|^{2} d x \\
& \leq \liminf _{n \rightarrow \infty} \int_{A_{\delta}}\left|\operatorname{curl} \mathbf{V}_{n}\right|^{2} d x \leq\left|A_{\delta}\right|
\end{aligned}
$$

Thus $\left|A_{\delta}\right|=0$. Since $\delta>0$ is arbitrary, we see that $|\operatorname{curl} \mathbf{V}(x)| \leq 1$ a.e. in $\Omega$. From this we can also see that $\{\mathbf{V} \in K ; \mid$ curl $\mathbf{V} \mid \leq 1\}$ is a closed convex subset in $L^{2}\left(\Omega, \mathbb{R}^{3}\right)$.

Now we have the following theorem.

Theorem 11. Under (H.1), (H.2), and (H.4), $\mathbf{H}^{(p)}(x, t)$ has a unique limit $\mathbf{H}^{(\infty)}(x, t)$ as $p \rightarrow \infty$ such that

$$
\begin{aligned}
\mathbf{F}-\mathbf{H}_{t}^{(\infty)} & \in \partial I_{\infty}\left[\mathbf{H}^{(\infty)}\right] \quad \text { a.e. } t \in[0, T], \\
\mathbf{H}^{(\infty)}(x, 0) & =\mathbf{H}_{0}(x) ;
\end{aligned}
$$

that is to say,

$$
\begin{aligned}
& I_{\infty}[\mathbf{V}]-I_{\infty}\left[\mathbf{H}^{(\infty)}\right] \\
& \quad \geq \int_{\Omega}\left(\mathbf{F}-\mathbf{H}_{t}^{(\infty)}\right) \cdot\left(\mathbf{V}-\mathbf{H}^{(\infty)}\right) d x
\end{aligned}
$$

for a.e. $t \in[0, T]$ for all $\mathbf{V} \in K$ and

$$
\int_{\Omega}\left|\mathbf{H}(x, t)-\mathbf{H}_{0}(x)\right|^{2} d x \longrightarrow 0 \quad \text { as } t \longrightarrow+0 .
$$


Proof.

Step 1 (the uniqueness of the solution of (83)). We follow Yin [13]. Let $\mathbf{H}_{1}^{(\infty)}$ and $\mathbf{H}_{2}^{(\infty)}$ be two solutions of (83). Then we have

$$
\begin{aligned}
0 & =I_{\infty}\left[\mathbf{H}_{2}^{(\infty)}\right]-I_{\infty}\left[\mathbf{H}_{1}^{(\infty)}\right] \\
& \geq \int_{\Omega}\left(\mathbf{F}-\mathbf{H}_{1, t}^{(\infty)}\right) \cdot\left(\mathbf{H}_{2}^{(\infty)}-\mathbf{H}_{1}^{(\infty)}\right) d x, \\
0 & =I_{\infty}\left[\mathbf{H}_{1}^{(\infty)}\right]-I_{\infty}\left[\mathbf{H}_{2}^{(\infty)}\right] \\
& \geq \int_{\Omega}\left(\mathbf{F}-\mathbf{H}_{2, t}^{(\infty)}\right) \cdot\left(\mathbf{H}_{1}^{(\infty)}-\mathbf{H}_{2}^{(\infty)}\right) d x .
\end{aligned}
$$

Adding these inequalities, we have

$$
\int_{\Omega}\left(\mathbf{H}_{2, t}^{(\infty)}-\mathbf{H}_{1, t}^{(\infty)}\right) \cdot\left(\mathbf{H}_{2}^{(\infty)}-\mathbf{H}_{1}^{(\infty)}\right) d x \leq 0 .
$$

Therefore

$$
\frac{d}{d t} \int_{\Omega}\left|\mathbf{H}_{2}^{(\infty)}-\mathbf{H}_{1}^{(\infty)}\right|^{2} d x \leq 0,
$$

and so we have

$$
\begin{aligned}
& \int_{\Omega}\left|\mathbf{H}_{2}^{(\infty)}(x, t)-\mathbf{H}_{1}^{(\infty)}(x, t)\right|^{2} d x \\
& \quad \leq \int_{\Omega}\left|\mathbf{H}_{2}^{(\infty)}(x, 0)-\mathbf{H}_{1}^{(\infty)}(x, 0)\right|^{2} d x=0
\end{aligned}
$$

for a.e. $t \in[0, T]$. Hence $\mathbf{H}_{1}^{(\infty)}(x, t)=\mathbf{H}_{2}^{(\infty)}(x, t)$ in $Q_{T}$.

Step 2 (existence of the limit solution). (1) Since (H.4) implies that

$$
\frac{1}{p} \int_{\Omega}\left|\operatorname{curl} \mathbf{H}_{0}\right|^{2} d x \leq \frac{1}{2}|\Omega|
$$

for any $p \geq 2$, we notice that the right hand sides of (50) and (56) are independent of $p \geq 2$. Therefore we have

$$
\begin{gathered}
\sup _{t \in[0, T]} \int_{\Omega}\left|\mathbf{H}^{(p)}\right|^{2} d x+\iint_{Q_{T}}\left|\operatorname{curl} \mathbf{H}^{(p)}\right|^{p} d x d t \leq C_{1}, \\
\iint_{Q_{t}}\left|\mathbf{H}_{t}^{(p)}\right|^{2} d x d t+\frac{1}{p_{t \in[0, T]}} \sup _{\Omega}\left|\operatorname{curl} \mathbf{H}^{(p)}\right|^{p} d x \leq C_{2},
\end{gathered}
$$

where $C_{1}$ and $C_{2}$ are independent of $p$. Therefore for any subsequence $\left\{\mathbf{H}^{\left(p^{\prime}\right)}\right\}$, there exists a subsequence $\left\{\mathbf{H}^{\left(p^{\prime \prime}\right)}\right\}$ such that

$$
\mathbf{H}^{\left(p^{\prime \prime}\right)} \longrightarrow \mathbf{H}^{(\infty)}
$$

strongly in $L^{2}\left(Q_{T}\right)$, weakly in $L^{2}\left(0, T ; W^{1, p}(\Omega)\right)$,

$$
\begin{aligned}
& \mathbf{H}^{\left(p^{\prime \prime}\right)} \longrightarrow \mathbf{H}^{(\infty)} \quad \text { a.e. in } Q_{T} \text {, } \\
& \operatorname{curl} \mathbf{H}^{\left(p^{\prime \prime}\right)} \longrightarrow \operatorname{curl} \mathbf{H}^{(\infty)}, \\
& \mathbf{H}_{t}^{\left(p^{\prime \prime}\right)} \longrightarrow \mathbf{H}_{t}^{(\infty)} \\
& \text { weakly in } L^{2}\left(Q_{T}\right) \text {, } \\
& \operatorname{div} \mathbf{H}^{(\infty)}=0 \quad \text { in } \Omega, \\
& \boldsymbol{\nu} \times \mathbf{H}^{(\infty)}(x, t)=0 \quad \text { on } \partial \Omega \times[0, T] . \\
& \iint_{Q_{T}}\left|\operatorname{curl} \mathbf{H}^{(p)}\right|^{p} d x d t \leq C_{1}, \\
& B_{\delta}=\left\{(x, t) \in Q_{T} ;\left|\operatorname{curl} \mathbf{H}^{(\infty)}(x, t)\right| \geq 1+\delta\right\} . \\
& (1+\delta)^{2}\left|B_{\delta}\right| \leq \iint_{B_{\delta}}\left|\operatorname{curl} \mathbf{H}^{(\infty)}\right|^{2} d x d t \\
& \leq \liminf _{p^{\prime \prime} \rightarrow \infty}\left\{\iint_{B_{\delta}}\left|\operatorname{curl} \mathbf{H}^{\left(p^{\prime \prime}\right)}\right|^{p^{\prime \prime}} d x d t\right\}^{1 / p^{\prime \prime}}\left|B_{\delta}\right|^{1-1 / p^{\prime \prime}} \\
& \leq \lim _{p^{\prime \prime} \rightarrow \infty} C_{1}^{1 / p^{\prime \prime}}\left|B_{\delta}\right|^{1-1 / p^{\prime \prime}}=\left|B_{\delta}\right| \text {. }
\end{aligned}
$$

Thus we see that $\left|B_{\delta}\right|=0$. Since $\delta>0$ is arbitrary, we see that (2) holds.

(3) Clearly the first equation of (83) is equivalent to

$$
\int_{\Omega}\left(\mathbf{F}-\mathbf{H}_{t}^{(\infty)}\right) \cdot\left(\mathbf{V}-\mathbf{H}^{(\infty)}\right) d x \leq 0 \quad \text { a.e. } t \in[0, T]
$$

for any $\mathbf{V} \in H_{0}^{2}(\operatorname{curl}$, div0, $\Omega)$ with $|\operatorname{curl} \mathbf{V}| \leq 1$. Since $\mathbf{H}^{\left(p^{\prime \prime}\right)}$ is a unique solution of

$$
\begin{aligned}
& \mathbf{F}-\mathbf{H}_{t} \in \partial I_{p^{\prime \prime}}[\mathbf{H}] \quad \text { a.e. } t \in[0, T], \\
& \mathbf{H}(x, 0)=\mathbf{H}_{0}(x),
\end{aligned}
$$

for any $\mathbf{V} \in H_{0}^{2}(\operatorname{curl}, \operatorname{div} 0, \Omega)$ with $|\operatorname{curl} \mathbf{V}| \leq 1$,

$$
\begin{aligned}
& I_{p^{\prime \prime}}[\mathbf{V}]-I_{p^{\prime \prime}}\left[\mathbf{H}^{p^{\prime \prime}}\right] \\
& \quad \geq \int_{\Omega}\left(\mathbf{F}-\mathbf{H}_{t}^{\left(p^{\prime \prime}\right)}\right) \cdot\left(\mathbf{V}-\mathbf{H}^{\left(p^{\prime \prime}\right)}\right) d x .
\end{aligned}
$$

Here we note that by hypothesis

$$
\begin{aligned}
I_{p^{\prime \prime}}[\mathbf{V}] & =\int_{\Omega} f_{p^{\prime \prime}}\left(x,|\operatorname{curl} \mathbf{V}|^{2}\right) d x \\
& \leq \frac{2 \Lambda}{p^{\prime \prime}} \int_{\Omega}|\operatorname{curl} \mathbf{V}|^{p^{\prime \prime}} d x \leq \frac{2 \Lambda}{p^{\prime \prime}}|\Omega| \longrightarrow 0
\end{aligned}
$$


as $p^{\prime \prime} \rightarrow \infty$. Since $\mathbf{H}^{\left(p^{\prime \prime}\right)} \rightarrow \mathbf{H}^{(\infty)}$ strongly in $L^{2}\left(Q_{T}\right)$ and $\mathbf{H}_{t}^{\left(p^{\prime \prime}\right)} \rightarrow \mathbf{H}_{t}^{(\infty)}$ weakly in $L^{2}\left(Q_{T}\right)$, we see that, for a.e. $t \in[0$, $T]$,

$$
\begin{aligned}
& \int_{\Omega}\left(\mathbf{F}-\mathbf{H}_{t}^{\left(p^{\prime \prime}\right)}\right) \cdot\left(\mathbf{V}-\mathbf{H}^{\left(p^{\prime \prime}\right)}\right) d x \\
& \longrightarrow \int_{\Omega}\left(\mathbf{F}-\mathbf{H}_{t}^{(\infty)}\right) \cdot\left(\mathbf{V}-\mathbf{H}^{(\infty)}\right) d x .
\end{aligned}
$$

Letting $p^{\prime \prime} \rightarrow \infty$ in (103) and using the fact that $I_{p^{\prime \prime}}\left[\mathbf{H}^{\left(p^{\prime \prime}\right)}\right] \geq$ 0 , we see that

$$
\int_{\Omega}\left(\mathbf{F}-\mathbf{H}_{t}^{(\infty)}\right) \cdot\left(\mathbf{V}-\mathbf{H}^{(\infty)}\right) d x \leq 0 .
$$

Thus we can see that $\mathbf{H}^{(\infty)}$ satisfies the first equation of (83).

(4) For the initial condition, it follows from

$$
\begin{aligned}
& \int_{\Omega}\left|\mathbf{H}^{(\infty)}(x, t)-\mathbf{H}_{0}(x)\right|^{2} d x \\
& =\lim _{p^{\prime \prime} \rightarrow \infty} \int_{\Omega}\left|\mathbf{H}^{\left(p^{\prime \prime}\right)}(x, t)-\mathbf{H}_{0}\right|^{2} d x \\
& \leq \underset{p^{\prime \prime} \rightarrow \infty}{\limsup } \int_{\Omega}\left|\int_{0}^{t} \mathbf{H}_{\tau}^{\left(p^{\prime \prime}\right)}(x, \tau) d \tau\right|^{2} d x \\
& \leq \underset{p^{\prime \prime} \rightarrow \infty}{\limsup } \int_{\Omega} \int_{0}^{t}\left|\mathbf{H}_{\tau}^{\left(p^{\prime \prime}\right)}(x, \tau)\right|^{2} d \tau d x \\
& \leq t \underset{p^{\prime \prime} \rightarrow \infty}{\limsup }\left\|\mathbf{H}_{t}^{\left(p^{\prime \prime}\right)}\right\|_{L^{2}\left(\mathrm{Q}_{T}\right)}^{2} \longrightarrow 0
\end{aligned}
$$

as $t \rightarrow+0$. Hence $\mathbf{H}^{(\infty)}$ is a solution of (83). Since the solution of (83) is unique, we can replace $p^{\prime \prime}$ in Step 2 by any p.

Now we show the Hölder continuity of the limit solution.

Theorem 12. The above limit solution $\mathbf{H}^{(\infty)}$ of (83) is Hölder continuous in $\overline{Q_{T}}$.

Proof. We put $\mathbf{K}(x, t)=\mathbf{H}^{(\infty)}(x, t)$ for brevity. Since $\operatorname{divK}=0$ in $\Omega$ for a.e. $t \in[0, T]$, we have

$$
-\Delta \mathbf{K}=\operatorname{curl}(\operatorname{curl} \mathbf{K})
$$

in the sense of distribution. Since $\mathbf{H}^{(\infty)} \in W^{1, p}(\Omega)$ for a.e. $t \in[0, T]$, the tangent trace is well defined, and since $\boldsymbol{v} \times \mathbf{H}^{(p)}(x, t)=\mathbf{0}$ on $\partial \Omega \times[0, T], \mathbf{H}^{(p)}(x, t) \rightarrow$ $\mathbf{H}^{(\infty)}(x, t)$ weakly in $W^{1, p}(\Omega)$ for a.e. $t \in[0, T]$, we have $\boldsymbol{v} \times \mathbf{H}^{(\infty)}(x, t)=0$ on $\partial \Omega$ for a.e. $t \in[0, T]$. Moreover, by Step 2 in the proof of Theorem 11, for any $q>1, \operatorname{curl}^{(\infty)} \epsilon$
$L^{q}(\Omega)$ for a.e. $t \in[0, T]$. Thus $\mathbf{K}$ satisfies that, for a.e. $t \in[0, T]$,

$$
\begin{aligned}
& -\Delta \mathbf{K}=\operatorname{curl}(\operatorname{curl} \mathbf{K}) \quad \text { in } \Omega, \\
& \operatorname{divK}=0 \quad \text { in } \Omega, \\
& \boldsymbol{\nu} \times \mathbf{K}=0 \quad \text { on } \partial \Omega .
\end{aligned}
$$

Since curl $K \in L^{q}(\Omega)$ for any $q>1$, it follows from [6, Proposition 5.1 and Remark 5.1(ii)] that $\mathbf{K} \in W^{1, q}\left(\Omega, \mathbb{R}^{3}\right)$ and

$$
\|\mathbf{K}\|_{W^{1, q}(\Omega)} \leq C\|\operatorname{curl} \mathbf{K}\|_{L^{q}(\Omega)} \leq C(q),
$$

where $C(q)$ is independent of $t$. By the Sobolev embedding theorem, for a.e. $t \in[0, T], \mathbf{K}(x, t)=\mathbf{H}^{(\infty)}(x, t) \in C^{\alpha}(\bar{\Omega})$ for any $0<\alpha<1$. The Hölder continuity with respect to $t$ follows from the similar argument of the proof of Theorem 10. lowing.

Finally we assume that the function $f_{p}$ satisfies the fol-

(H.5) $\left(f_{p}^{\prime}\left(x, s^{2}\right) s\right)^{p /(p-1)} \leq f_{p}^{\prime}\left(x, s^{2}\right) s^{2}$ for $s \geq 0$.

Remark 13. When $f_{p}(x, s)=(2 / p) a(x) s^{p / 2}$ and $a(x) \leq 1$, it is easily shown that $f_{p}$ satisfies (H.4).

Theorem 14. Under conditions (H.1), (H.2), and (H.5), there exists a nonnegative measurable function $a(x, t)$ such that

$$
\mathbf{H}_{t}^{(\infty)}+\operatorname{curl}\left[a(x, t) \operatorname{curl} \mathbf{H}^{(\infty)}\right]=\mathbf{F} \quad \text { in } Q_{T}
$$

in the distribution sense, and

$$
\operatorname{supp} a \subset N:=\left\{(x, t) \in Q_{T} ;\left|\operatorname{curl} \mathbf{H}^{(\infty)}(x, t)\right|=1\right\} \text {. }
$$

Proof. Put $\mathbf{A}_{p}=f_{p}^{\prime}\left(x,\left|\operatorname{curl} \mathbf{H}^{(p)}\right|^{2}\right)$ curl $\mathbf{H}^{(p)}$. Taking the inner product of (16) and $\mathbf{V} \in L^{2}\left(0, T ; H_{0}^{p}(\operatorname{curl}, \operatorname{div} 0, \Omega)\right)$, we have

$$
\begin{aligned}
& \iint_{Q_{T}}\left(\mathbf{H}_{t}^{(p)} \cdot \mathbf{V}+\mathbf{A}_{p} \cdot \operatorname{curl} \mathbf{V}\right) d x d t \\
& \quad=\iint_{Q_{T}} \mathbf{F} \cdot \mathbf{V} d x d t
\end{aligned}
$$

Since $\left|\mathbf{A}_{p}\right| \leq \Lambda\left|\operatorname{curl} \mathbf{H}^{(p)}\right|^{p-1}$ by hypothesis (H.1), $\left\{\mathbf{A}_{p}\right\}$ is bounded in $L^{2}\left(0, T ; L^{p^{\prime}}(\Omega)\right)$. Therefore there exists a subsequence $\left\{\mathbf{A}_{p_{k}}\right\}$ such that $\mathbf{A}_{p_{k}} \rightarrow \mathbf{A}$ weakly in $L^{2}\left(0, T ; L^{p^{\prime}}(\Omega)\right)$ as $k \rightarrow \infty$. Since $\mathbf{H}_{t}^{(p)} \rightarrow \mathbf{H}_{t}^{(\infty)}$ weakly in $L^{2}\left(Q_{T}\right)$ from (95), letting $k \rightarrow \infty$ in (113) with $p=p_{k}$, we have

$$
\begin{aligned}
& \iint_{Q_{T}}\left(\mathbf{H}_{t}^{(\infty)} \cdot \mathbf{V}+\mathbf{A} \cdot \operatorname{curl} \mathbf{V}\right) d x d t \\
& \quad=\iint_{Q_{T}} \mathbf{F} \cdot \mathbf{V} d x d t
\end{aligned}
$$


On the other hand, from (113) with $\mathbf{V}=\mathbf{H}^{(p)}$, we have

$$
\begin{aligned}
& \iint_{Q_{T}}\left(\frac{1}{2} \frac{d}{d t}\left|\mathbf{H}_{t}^{(p)}\right|^{2}+\mathbf{A}_{p} \cdot \operatorname{curl} \mathbf{H}^{(p)}\right) d x d t \\
& \quad=\iint_{Q_{T}} \mathbf{F} \cdot \mathbf{H}^{(p)} d x d t .
\end{aligned}
$$

Hence, using (93) with $p^{\prime \prime}=p$,

$$
\begin{aligned}
& \frac{1}{2} \iint_{\Omega}\left|\mathbf{H}^{(p)}(x, T)\right|^{2} d x-\frac{1}{2} \int_{\Omega}\left|\mathbf{H}_{0}(x)\right|^{2} d x \\
& \quad+\iint_{Q_{T}} f_{p}^{\prime}\left(x,\left|\operatorname{curl} \mathbf{H}^{(p)}\right|^{2}\right)\left|\operatorname{curl} \mathbf{H}^{(p)}\right|^{2} d x d t \\
& \quad=\iint_{Q_{T}} \mathbf{F} \cdot \mathbf{H}^{(p)} d x d t \longrightarrow \iint_{Q_{T}} \mathbf{F} \cdot \mathbf{H}^{(\infty)} d x d t
\end{aligned}
$$

$$
\begin{aligned}
\iint_{Q_{T}}|\mathbf{A}| d x d t & \leq \liminf _{k \rightarrow \infty} \iint_{Q_{T}}\left|\mathbf{A}_{p_{k}}\right| d x d t=\liminf _{k \rightarrow \infty} \iint_{Q_{T}} f_{p}^{\prime}\left(x,\left|\operatorname{curl} \mathbf{H}^{\left(p_{k}\right)}\right|^{2}\right)\left|\operatorname{curl} \mathbf{H}^{\left(p_{k}\right)}\right| d x d t \\
& \leq \liminf _{k \rightarrow \infty}\left\{\iint_{\mathrm{Q}_{T}}\left(f_{p}^{\prime}\left(x,\left|\operatorname{curl} \mathbf{H}^{\left(p_{k}\right)}\right|^{2}\right)\left|\operatorname{curl}^{\left(p_{k}\right)}\right|\right)^{p_{k} /\left(p_{k}-1\right)} d x d t\right\}^{1-1 / p_{k}}(T|\Omega|)^{1 / p_{k}} \\
& \leq \liminf _{k \rightarrow \infty}\left\{\iint_{\mathrm{Q}_{T}} f_{p}^{\prime}\left(x,\left|\operatorname{curl} \mathbf{H}^{\left(p_{k}\right)}\right|^{2}\right)\left|\operatorname{curl} \mathbf{H}^{\left(p_{k}\right)}\right|^{2} d x d t\right\}^{1-1 / p_{k}}(T|\Omega|)^{1 / p_{k}}=\iint_{\mathrm{Q}_{T}} \mathbf{A} \cdot \operatorname{curl} \mathbf{H}^{(\infty)} d x d t \\
& \leq \iint_{\mathrm{Q}_{T}}|\mathbf{A}| d x d t .
\end{aligned}
$$

Here the last inequality is based on the fact that $\left|\operatorname{curl} \mathbf{H}^{(\infty)}\right| \leq$ 1. This implies that $|\mathbf{A}|=\mathbf{A} \cdot \operatorname{curl} \mathbf{H}^{(\infty)}$, so $\mathbf{A}(x, t)$ and $\mathbf{H}^{(\infty)}(x, t)$ are linearly dependent. Thus there exists a measurable function $a(x, t)$ such that $\mathbf{A}(x, t)=a(x, t) \operatorname{curl} \mathbf{H}^{(\infty)}(x, t)$ where $a(x, t):=0$ if $\mathbf{H}^{(\infty)}(x, t)=\mathbf{0}$. Since $\mathbf{H}_{t}^{(p)}+\operatorname{curl} \mathbf{A}_{p}=\mathbf{F}$ in $Q_{T}$ and $\mathbf{H}_{t}^{\left(p_{k}\right)} \rightarrow \mathbf{H}_{t}^{(\infty)}$ weakly in $L^{2}\left(Q_{T}\right)$ and $\mathbf{A}_{p_{k}} \rightarrow \mathbf{A}$ weakly in $L^{2}\left(0, T ; L^{p^{\prime}}(\Omega)\right)$, we have

$$
\mathbf{H}_{t}^{(\infty)}+\operatorname{curl} \mathbf{A}=\mathbf{F}
$$

in the distribution sense. Since

$$
0 \leq|\mathbf{A}|=\mathbf{A} \cdot \operatorname{curl} \mathbf{H}^{(\infty)}=a(x, t)\left|\operatorname{curl} \mathbf{H}^{(\infty)}\right|^{2},
$$

the function $a(x, t)$ is nonnegative. Moreover, if $0<$ $\left|\operatorname{curl} \mathbf{H}^{(\infty)}(x, t)\right|<1$, then

$$
\begin{gathered}
a(x, t)\left|\operatorname{curl} \mathbf{H}^{(\infty)}(x, t)\right|=|\mathbf{A}(x, t)| \\
=a(x, t)\left|\operatorname{curl} \mathbf{H}^{(\infty)}(x, t)\right|^{2} .
\end{gathered}
$$

So we have $a(x, t)=0$. Hence supp $a \subset N$. This completes the proof. as $p \rightarrow \infty$. From (114) with $\mathbf{V}=\mathbf{H}^{(\infty)}$, we have

$$
\begin{aligned}
& \frac{1}{2} \iint_{\Omega}\left|\mathbf{H}^{(\infty)}(x, T)\right|^{2} d x-\frac{1}{2} \int_{\Omega}\left|\mathbf{H}_{0}(x)\right|^{2} d x \\
& \quad+\iint_{Q_{T}} \mathbf{A} \cdot \operatorname{curl} \mathbf{H}^{(\infty)} d x d t \\
& \quad=\iint_{Q_{T}} \mathbf{F} \cdot \mathbf{H}^{(\infty)} d x d t .
\end{aligned}
$$

as $p \rightarrow \infty$. Since $\mathbf{A}_{p_{k}} \rightarrow \mathbf{A}$ weakly in $L^{1}\left(Q_{T}\right)$, using the Hölder inequality and (H.5), we have

\section{Conflict of Interests}

The author declares that there is no conflict of interests regarding the publication of this paper.

\section{References}

[1] L. Prigozhin, "On the Bean critical-state model in superconductivity," European Journal of Applied Mathematics, vol. 7, no. 3, pp. 237-247, 1996.

[2] P. G. de Gennes, Superconductivity of Metals and Alloys, Benjamin, 1966.

[3] H.-M. Yin, B. Q. Li, and J. Zou, "A degenerate evolution system modeling Bean's critical-state type-II superconductors," Discrete and Continuous Dynamical Systems A, vol. 8, no. 3, pp. 781-794, 2002.

[4] C. P. Bean, "Magnetization of high-field superconductors," Reviews of Modern Physics, vol. 36, no. 1, pp. 31-39, 1964. 
[5] R. Dautray and J. L. Lions, Mathematical Analysis and Numerical Methods for Science and Technology, vol. 3, Springer, New York, NY, USA, 1990.

[6] C. Amrouche and N. E. Seloula, " $L^{p}$-theory for vector potentials and Sobolev's inequalities for vector fields: application to the stokes equations with pressure boundary conditions," Mathematical Models and Methods in Applied Sciences, vol. 23, no. 1, pp. 37-92, 2013.

[7] J. Aramaki, " $L^{p}$ theory for the div-curl system," International Journal of Mathematical Analysis, vol. 8, no. 5-8, pp. 259-271, 2014.

[8] X.-B. Pan, "On a quasilinear system involving the operator curl," Calculus of Variations and Partial Differential Equations, vol. 36, no. 3, pp. 317-342, 2009.

[9] H. Brezis, Opérateurs maximaux monotones et semi-groupes de contractions dans les espaces de Hilbert, vol. 5 of Mathematics Studies, North-Holland Publishing, 1973.

[10] M. Struwe, Variational Methods: Applications to Nonlinear Partial Differential Equations and Hamiltonian Systems, Springer, 2007.

[11] L. C. Evans, Partial Differential Equations, AMS, 2010.

[12] W. Takahashi, Nonlinear Functional Analysis, Yokohama Publishers, Yokohama, Japan, 2010.

[13] H. M. Yin, "On a p-Laplacian type of evolution system and application to the Bean model in the type-II superconductivity theory," Quarterly of Applied Mathematics, vol. 59, no. 1, pp. 4766, 2001. 


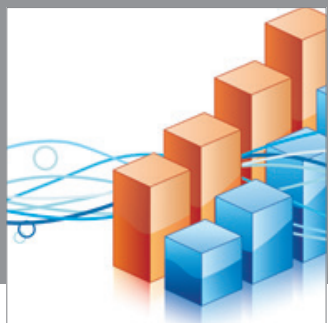

Advances in

Operations Research

mansans

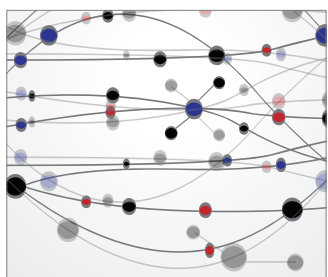

The Scientific World Journal
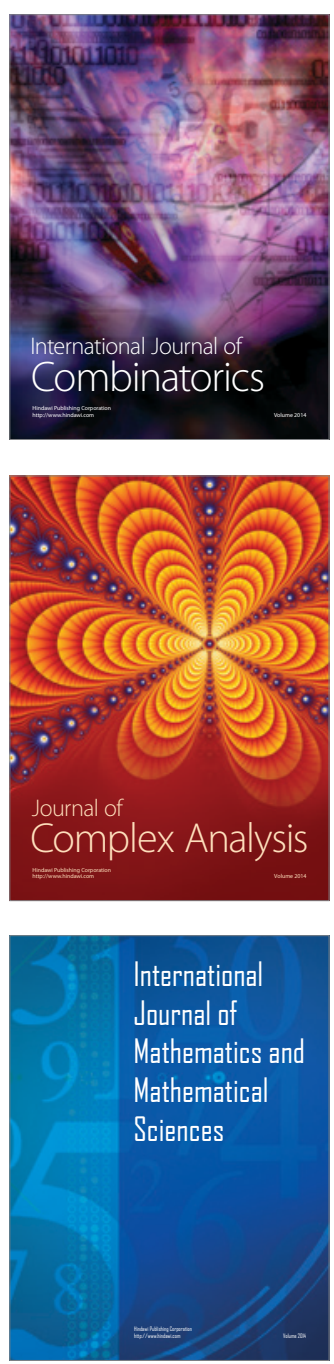
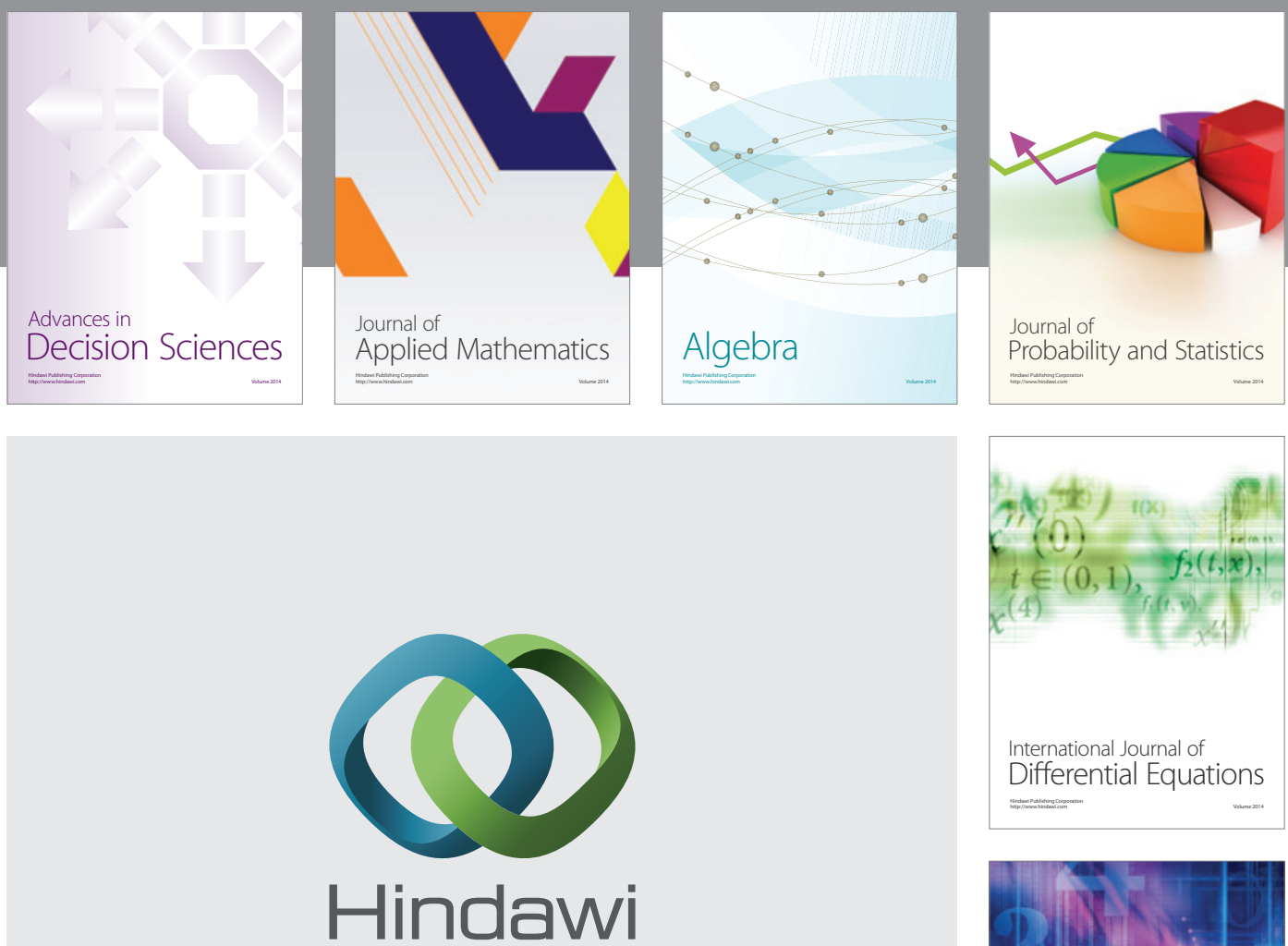

Submit your manuscripts at http://www.hindawi.com
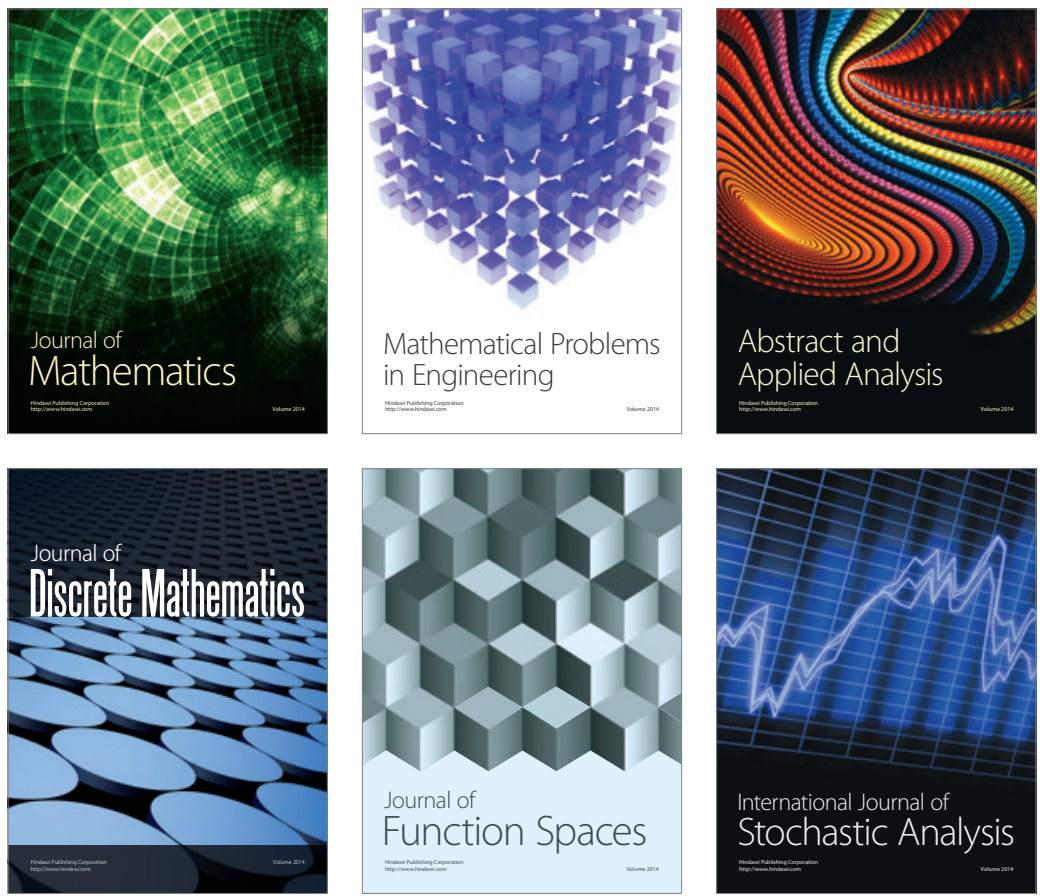

Journal of

Function Spaces

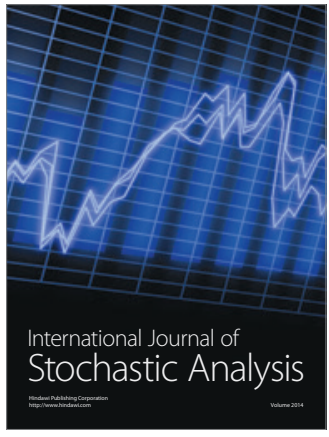

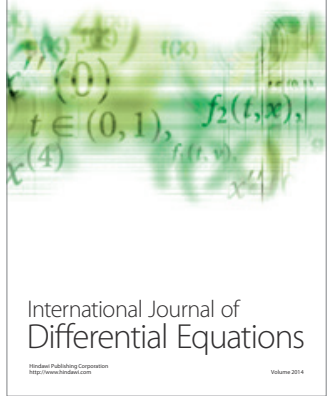
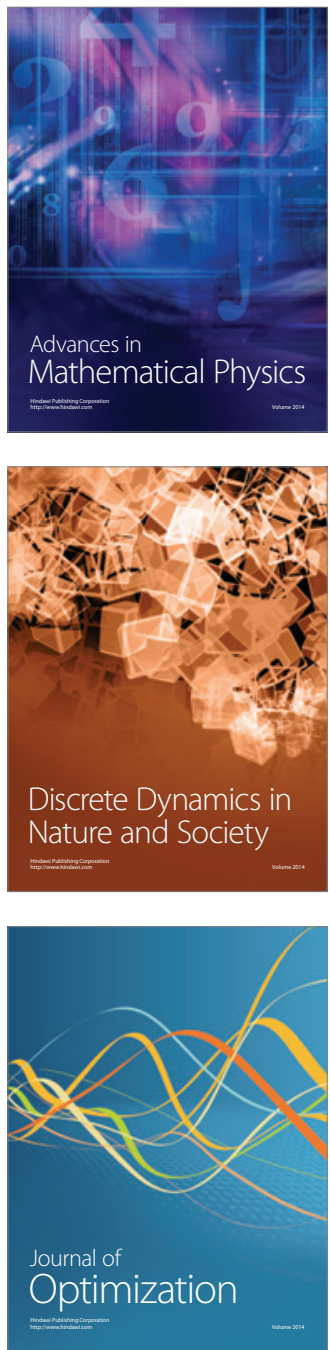